\title{
Architecture Synthesis Basis for the Hanford Cleanup System: First Issue
}

Compiled by

J. J. Holmes

Date Published

June 1994

Prepared for the U.S. Department of Energy Office of Environmental Restoration and Waste Management

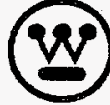

Westinghouse

P.O. Box 1970

Hantord Company Richland, Washington 99352

Hanford Operations and Engineering Contractor for the

U.S. Department of Energy under Contract DE-AC06-87RL10930 


\section{RELEASE AUTHORIZATION}

Document Number: WHC-EP-0779, Draft

Document Title:

Architecture Synthesis Basis for the Hanford Cleanup

System: First Issue

Release Date:

July 25,1994

This document was reviewed following the procedures described in WHC-CM-3-4 and is:

APPROVED FOR PUBLIC RELEASE

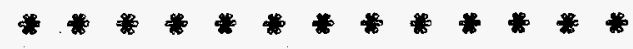

WHC Information Release Administration Specialist:

Tin. Bostar

M. N. Boston

(Signature)

$7 / 25 / 94$

(Date) 


\section{DISCLAIMER}

This report was prepared as an account of work sponsored by an agency of the United States Government. Neither the United States Government nor any agency thereof, nor any of their employees, make any warranty, express or implied, or assumes any legal liability or responsibility for the accuracy, completeness, or usefulness of any information, apparatus, product, or process disclosed, or represents that its use would not infringe privately owned rights. Reference herein to any specific commercial product, process, or service by trade name, trademark, manufacturer, or otherwise does not necessarily constitute or imply its endorsement, recommendation, or favoring by the United States Government or any agency thereof. The views and opinions of authors expressed herein do not necessarily state or reflect those of the United States Government or any agency thereof. 


\section{DISCLAIMER}

Portions of this document may be illegible in electronic image products. Images are produced from the best available original document. 
ARCHITECTURE SYNTHESIS BASIS FOR THE

HANFORD CLEANUP SYSTEM: FIRST ISSUE

\author{
J. J. Holmes
}

\begin{abstract}
This document describes a set of candidate alternatives proposed to accomplish the Hanford Cleanup system functions defined in a previous work. Development of alternatives is part of a sequence of system engineering activities which lead to definition of all the products which, when completed, accomplish the cleanup mission. The alternative set is developed to functional level four or higher depending on need.
\end{abstract}




\section{CONTENTS}

1.0 INTRODUCTION . . . . . . . . . . . . . . . . . . . . . . . . . . . .

2.0 SYSTEMS ARCHITECTURE DEFINED .................. 2-1

3.0 PREFERRED AlTERNATIVES . . . . . . . . . . . 3-1

4.0 ARCHITECTURE DEPTH .................. 4-1

4.1 MANAGE PROGRAM ........................... 4-

4.1.1 Establish Management System .......... 4-3

4.1.2 Perform Systems Engineering . . . . . . . . 4-4

4.2 ACQUIRE MISSION ESSENTIAL CAPABILITIES . . . . . . . 4-5

4.3 OBTAIN PUBLIC ACCEPTANCE ............... . . . . . 4

4.3.1 Identify Activities . . . . . . . . . . 4-7

4.3.2 Identify Information Needs For Public Groups . . . . . 4-8

4.4 REMEDY UNSAFE AND UNACCEPTABLE CONDITIONS . . . . . . . 4-9

4.4.1 Deactivate Facilities ........... . 4-10

4.4.2 Remediate Tank Waste ........... 4-28

4.4.3 Remedy Solid Waste ............ 4-48

4.4.4 Remedy/Restore Sites, Facilities, and Groundwater . 4-65

4.4.5 Manage Aqueous Wastes ......... 4-67

4.4.6 Correct Unsafe Infrastructure Conditions ... . . 4-72

4.4.7 Store, Treat, Disposition Special Nuclear Material/
Nuclear Material/Nuclear Fuel Materials . . . . 4-72

4.5 TRANSITION RESOURCES FOR BENEFICIAL. USE ........ . . 4-78

4.5.1 Determine Beneficial Uses of Resources . . . . 4-78

5.0 REFERENCES ..................... 5-1

\section{LIST OF TABLES}

4-1 Architecture Limits ................... 4-2 


\section{LIST OF TERMS}

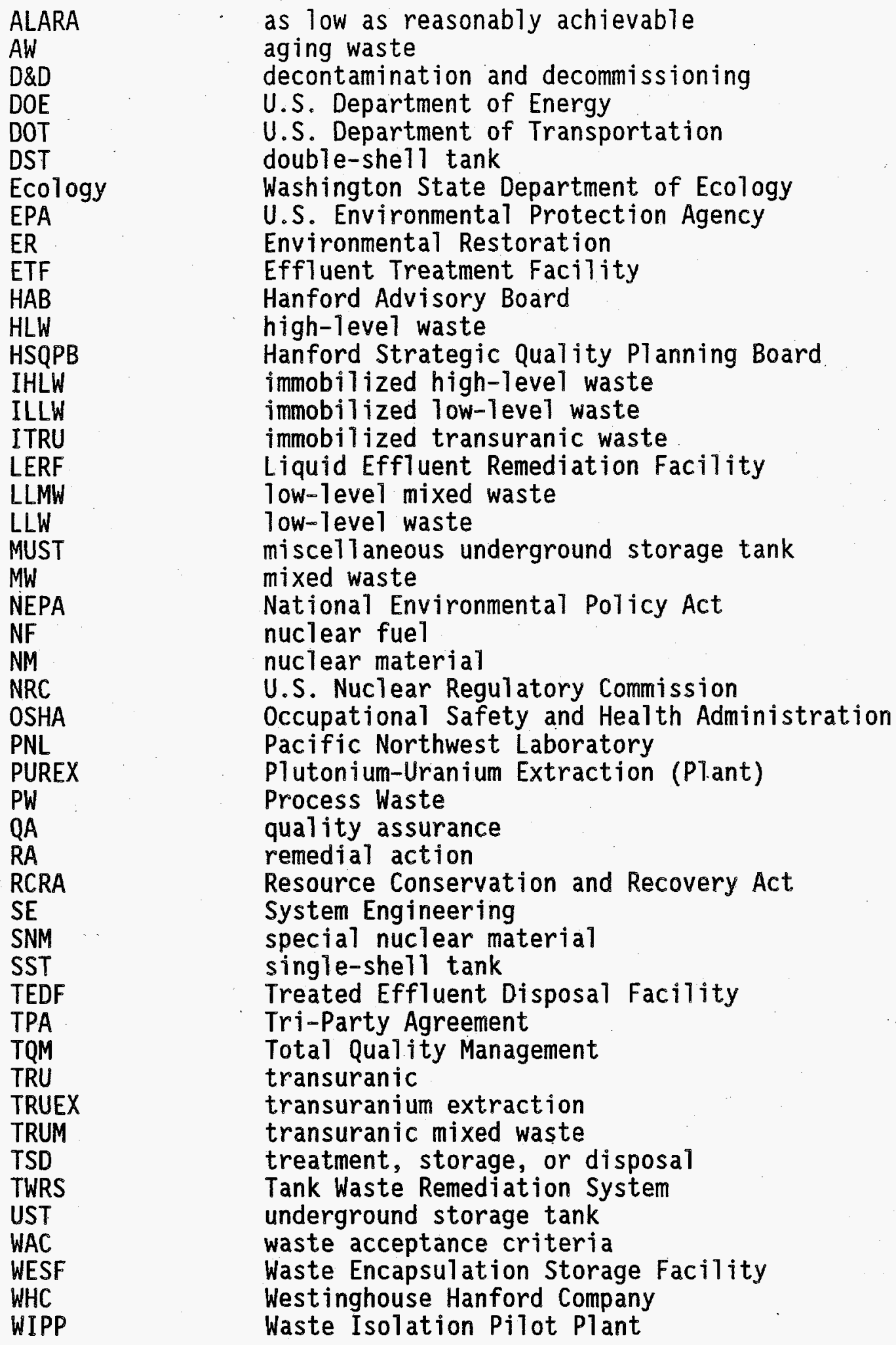


This page intentionally left blank. 


\section{ARCHITECTURE SYNTHESIS BASIS FOR THE HANFORD CLEANUP SYSTEM, FIRST ISSUE}

\subsection{INTRODUCTION}

This document describes the architectural alternatives for the top levels of the Hanford Cleanup Mission systems engineering analysis. The information presented herein continues the systems engineering work described in Systems Engineering Functions and Requirements for the Hanford Cleanup Mission, First Issue (Holmes 1994) by developing a systems architecture which provides a physical basis to the functions of (Holmes 1994).

The overall goal of the systems analysis is to completely specify all components of the Hanford Cleanup system. This work is based on the concepts described in the draft Military Standard Mil-Std-499b (ref 2), and the Systems Engineering Management Guide, published by the Defense Systems Management College, Fort Belvoir, Virginia (ref 3).

The Systems Engineering path being followed consists of the following steps:

1. Analysis of customer requirements.

2. Development of mission, scope, and problem statements.

3. Definition of conditions to be changed (input/output).

4. Functional analysis.

5. External interface definitions.

6. External requirements scope.

7. Site-level Systems Architecture development.

8. Definition of top level products which meet the architectural and functional requirements and allocation of all functions, functional interfaces, functional requirements (inputs/outputs), and external interfaces to each product.

9. Development of a product hierarchy (i.e., product tree).

10. Specification of all top level products to the extent that assigned WHC organizations or the various Hanford contractors can develop lower level system product specifications.

11. Definition (by Systems Engineering) of all the lower-level products needed to complete the cleanup mission by the organizations responsible for conducting specific cleanup activities. 
Reference 1 documents steps 1-6. The customer (Item 1) is currently defined as the Hanford Strategic Quality Planning Board (HSQPB). However, in reference 1 the "customer" was defined as the attendees at the Executive Systems Engineering Workshops held Apri1 26/27 and May 10/11, 1993. The workshop included representatives from senior management from all Hanford contractors. The results of reference 1 have been reviewed with the HSQPB and form the basis for Cleanup Mission strategy being developed by HSQPB.

The product specifications developed by Systems Engineering process may or may not be coincident with existing cleanup plans. In many cases lower level product design will not have started yet. In others, the lower level design is complete and acquisition is underway. In a few others, acquisition is complete. For the system to work properly all products must be designed or retrofit to meet the top level system derived and allocated product specifications. 


\subsection{SYSTEMS ARCHITECTURE DEFINED}

The Systems Engineering process often proceeds from relatively abstract mission and functional analyses to a point where real world choices must be made. The first encounter with "system choices" usually occurs during functional decomposition (step 4). Often it is not possible to decompose to a lower level if some physical specification of the senior function is not made. The choices made at the senior function level are often called systems architectures. Architecture choices for high-level functions in complex systems are usually strategic in nature. As the functional levels decrease, the choices which specify a function become less strategic and more closely aligned with definite action, or acquisition of a physical item.

The functional analysis provided in reference 1 was constructed without any specific systems architecture in mind. However, in some cases a predetermined or inadvertently assumed architecture is evident. An example of this can be found in function 4.3 where retrieval, packaging, and disposal of solid wastes is implicitly assumed in preference to other architectures such as in-place disposal. Similar assumptions can be found throughout the functional analysis. The danger in inadvertently assuming architecture is that a superior path may be overlooked. One of the prime reasons for conducting systems engineering is to ensure that the superior architectures are identified and utilized.

Not all functions will require architectural definition. Most high-level functions will require only a small amount of specification. However, at the highest functional levels, rather simplistic architectural statements can have a huge effect on systems design. As the architectural analys is proceeds to lower levels, architectural richness diminishes to the point where a)ternatives to achieve specific functional requirements are more appropriate to individual product design than systems level product definition. It should be emphasized that product design must also follow systems engineering principles and will include local architectures.

The process used here to define, confirm, or upgrade the assumed architectures involved creation of a small group (3-5) of experts in each functional area to develop architectures for each function to level four where appropriate. Each group was facilitated by a systems engineer from the WHC Systems Engineering Center of Excellence. The groups were asked to specify the minimum architecturat information needed to define the succeeding functional breakout. Any specifications which could be placed at a lower level were allocated downward to the appropriate function. As a result, only a few statements are needed to adequately specify each function. 
This page intentionally left blank. 


\subsection{PREFERRED ALTERNATIVES}

Candidate architectural alternatives may only cover a restricted range of functional need. A selection of favorable attributes from the alternative set often leads to a "synthesis" alternative which is superior to all others. This preferred synthesis alternative is often used in this document as the basis to validate the lower-level functional analyses and to allow continued architectural development at the lower levels.

The preferred synthesis alternative set forms the an initial candidate architecture for the entire system. Many of the architectural preferences included in this report are imbedded in the Hanford Federal Facility Agreement and Consent Order, TPA (ref 4), or other binding documents. Analys is of cost, risk, public preference and schedule implications for the total system remain to be completed before the preferred alternative set described here can be adopted as the reference architecture. Additionally, the reference architecture must be reviewed with the Hanford stakeholders and accepted by the system customer before installation as an authoritative baseline.

Regulatory and policy analysis also need to be conducted to insure that chosen candidates meet system external requirements. Cost and schedule estimates for the physical system alternatives, i.e., the hierarchy defined in the functional set 4.0 are documented in the Hanford Strategic Analysis(5).

Where the analyses indicated above reveal deficiencies; a more appropriate alternative wi11 be developed or chosen. However, a11 preferred alternatives 1 isted here are expected meet al1 app1icable external requirements and policies. One purpose of this document is to provide the basis for the reviews and analysis needed to test the systems architecture. 
This page intentionally left blank. 


\subsection{ARCHITECTURE DEPTH}

Architectural alternatives are developed to functional level four where appropriate. However, functions which should be developed by an assigned performing organization rather than by those developing top level architecture can appear at an elevated functional level. For example, functions 1.1 and 1.2 need top level architectural definition because of their strategic nature, while functions $1.3,1.4$, and 1.5 are sufficiently specific that these are more appropriately developed by program management staff. In such cases, further architectural work will become part of the follow-on systems engineering work of the responsible organizations.

The ability to proceed to decreasing levels can also be affected by a lack of sufficient information. For example, most of the second level functions of 2.0 require a parametric analys is to quantify the performance requirements of the acquisition system. Without quantification a11 that can be done is to list alternatives which may or may not drive the system in a favorable direction. For example, if we had specific knowledge that the project acquisition system was too slow or expensive to meet system needs, then alternatives which meet the cost and schedule requirements could be identified. In the absence of such information, alternative development has little value.

Table 1 shows the limits for architectural alternative development encountered in this work together with the associated rationale for termination of development.

As high-level system architectural specification progresses to lower levels, al ternatives are encountered which only have relevance to a specific system deliverable. At this point, further systems engineering needs to be conducted in the context of a the specific deliverable by those assigned to conduct the work. Alternative development may also be limited by inability to choose among widely disparate alternatives, or recognition that additional functional analysis is needed to properly account for all systems elements.

Table 4-1 provides the rationale for limiting architectural alternatives above level four. 
Table 4-1. Architecture Limits.

\begin{tabular}{|c|c|}
\hline Function number & Limit rationale \\
\hline $1.3,1.4,1.5$ & To be conducted by lower level assigned organizations. \\
\hline 1.6 & Additional Functional Decomposition Needed. \\
\hline 2.1 through 2.7 & Parametric Data needed. \\
\hline $3.3,3.4$ & To be conducted by lower level assigned organizations. \\
\hline $4.3 \cdot x \cdot x$ & To be conducted by lower level assigned organizations. \\
\hline $4.4 \cdot x \cdot x$ & $\begin{array}{l}\text { To be conducted by lower level assigned organizations. } \\
\text { Additional functional analysis needed. }\end{array}$ \\
\hline $4.5 . x \cdot x$ & To be conducted by lower level assigned organizations. \\
\hline 4.6 & $\begin{array}{l}\text { Architecture described elsewhere. See } 4.6 \text { in text } \\
\text { body. }\end{array}$ \\
\hline 4.7.x.x & To be conducted by lower level assigned organizations. \\
\hline $5.2,5.3$ & To be conducted by lower level assigned organizations. \\
\hline $5 . x \cdot x$ & To be conducted by lower level assigned organizations. \\
\hline
\end{tabular}

\subsection{MANAGE PROGRAM (1)}

The MANAGE PROGRAM function provides all program planning, management direction, evaluation, and the management system. This function does not directly contribute to the final state but provides the management needed to conduct the mission. The function includes specification of management policies and procedures, systems engineering, program definition, configuration management, scheduling, allocation of all resources, definition of performance criteria, and resolution of regulatory problems.

\section{ALTERNATIVES CONSIDERED}

1. Continue with current approach and use Value Engineering and Total Quality Management (TQM) to improve efficiency.

2. Employ issues based management methods to resolve near term problems and use strategic analysis to provide longer range planning basis.

3. Emphasize activity based management principles in which the cleanup work is subdivided into manageable projects or activity areas.

4. Use systems engineering to define the products needed to deliver the mission, and structure the products into a work plan using budget, risk, public preference, etc., as the scheduling parameters. 


\section{ARCHITECTURAL SYNTHESIS}

Although the existing management system is believed to meet all U.S. Department of Energy (DOE) orders and regulatory requirements, there is no reason to expect that it is adequate to efficiently deliver the cleanup mission. Much of the existing management infrastructure was derived from earlier operations which are not entirely appropriate for cleanup. Other approaches such as Value Engineering, TQM, strategic planning, and issues management can help but are not generally capable of designing a management system optimized for the purpose at hand.

Systems Engineering has been developed to provide high-performance designs for complex systems and has been effective in designing management systems in the private sector.

\section{SYNTHESIS DEFINITION}

Use systems engineering to redesign the management system for Hanford cleanup.

\subsubsection{Establish Management System (1.1)}

The ESTABLISH MANAGEMENT SYSTEM (1.1) function defines the procedures, policies, reporting, configuration management, etc., needed to manage the program. This function encompasses all routine management areas such as total quality, quality assurance (QA), personnel management, legal services, fiscal control, prime contracts, etc. This function also develops the organizational structure, evaluates the efficiency of management work, and develops appropriate corrective actions.

\section{ALTERNATIVES CONSIDERED}

1. Continue with existing approach.

2. Craft a mission wide management practice set which is optimized to deliver the cleanup mission.

3. Develop project/program/activity specific management methods appropriate to each area of interest.

4. Contract a high-performing management design organization to develop a management system for the cleanup mission.

5. Examine the management systems of successful government contractors and private industries and select the best features encountered for the cleanup management system. 


\section{ARCHITECTURAL SYNTHESIS}

The cleanup effort is so diverse that a single management approach which covers all elements will probably be inefficient. In addition, the mission contains numerous major contractors which will have their own individual management styles.

However, a potentially high-performing synthesis architecture can be developed from the alternatives listed above. The synthesis includes: (1) a two layered management system consisting of a high-level overlay that manages only those items needing top level direction and a lower tier system set which is tailored to the needs of the individual performing entities, and (2) identification and selection of high-performing management elements from the management systems of high-performing organizations.

\section{SYNTHESIS DEFINITION}

The management system will include a top level mission-wide element and a lower tier performer-specific system. The elements of both will be selected from management processes of successful government and private organizations.

\subsubsection{Perform Systems Engineering (1.2)}

The PERFORM SYSTEMS ENGINEERING (1.2) function performs SE activities for the mission.

\section{ALTERNATIVES CONSIDERED}

1. Develop a Unique Hanford cleanup mission specific systems engineering approach/methodology based on MIL-STD-499b, train the staff to properly use the Hanford. system, improve practice through lessons learned and TQM.

2. Use a small cadre of outside experts to train contractor personnel in the systems engineering approaches used in other industries.

3. Adopt in total a systems engineering approach which has proven successful in situations which closely approximate the cleanup mission.

4. Use an outside contractor to develop and establish an efficient systems engineering methodology for the cleanup mission. Companies with appropriate experience include Lockheed, TRW, and Ascent Logic among others. 
WHC-EP-0779

\section{ARCHITECTURAL SYNTHESIS}

A7ternatives 3 and 4 suggest sufficient outside experience exists that importation of an existing systems engineering approach is possible or that a contractor exists with sufficient experience to effectively craft a useful systems method. The Hanford cleanup mission is so unique that direct application of previously used approaches is inappropriate.

The remaining alternatives can be used to synthesize a workable systems approach consisting of (1) use of a small cadre of outside experts to work with resident systems engineering and technical personnel to define an initial (S.E.) approach, (2) conduct S.E. activities using the initial methods set, (3) improve the approach through practice, (4) continually strengthen capabilities by use of outside experts to review the S.E. work, and (5) add professional S.E. staff to supplement local talent.

\section{SYNTHESIS DEFINITION}

Develop a Hanford unique Systems Engineering approach using a combination of resident and outside experts, perfect the method through use, and strengthen resident capability by adding professional S.E. staff.

\subsection{ACQUIRE MISSION ESSENTIAL CAPABILITIES}

The ACQUIRE MISSION ESSENTIAL CAPABILITIES function provides a11 new intellectual and physical. resources. This includes personnel, consultants, services, supplies, equipment, construction projects, and subcontracts of al1 kinds.

\section{ALTERNATIVES CONSIDERED}

1. Continue present approach and use Value Engineering and TQM to improve the processes.

2. Collect and define acquisition elements which can be purchased, contracted, or constructed by a private offsite organization.

3. Collect and define acquisition elements which are better handled by other government agencies than by onsite capability and use this identified capability in place of existing approaches.

4. Redesign the entire acquisition process to focus exclusively on mission need. Utilize a graded approach to procurement/construction regulations which emphasizes a "loose" but legal interpretation of requirements, policies, and orders.

\section{ARCHITECTURAL SYNTHESIS}

Alternative 4 requires a parametric analysis to determine what acquisition characteristics need improvement to enable the mission to succeed. With the parametric analys is in place, alternatives which focus on particular areas with high-mission impact could be formulated. 
The remaining alternatives form the basis of a synthesis alternative consisting of continuing the present approach but with an emphasis on utilization of high-performing outside resources to provide mission essential capabilities. Improvement of the Acquisition system by TQM and Value Engineering should improve system quality.

\section{SYNTHESIS DEFINITION}

The acquisition system will emphasize use of high-performing offsite resources to perform specific tasks where cost, schedule, or quality advantages are evident. The acquisition system will be upgraded by continuous improvement using TQM and Value Engineering. Parametric modeling of the acquisition system will be conducted to provide the basis to re-engineer the process.

\subsection{OBTAIN PUBLIC ACCEPTANCE (3)}

The OBTAIN PUBLIC ACCEPTANCE function provides all the public interactions needed to complete the mission, such as public review of all plans, clarification of public values, and determining of public values as needed to minimize conflicts between the stakeholder interests and mission activities.

\section{ALTERNATIVES CONSIDERED}

1. Obtain public involvement on key programmatic decisions.

2. Utilize a flexible approach to resolution of public issues/concerns in which the public involvement plan is tailored to the needs of each issue constituency.

3. Design an approach to public involvement which is acceptable to the public and covers all situations.

4. Provide a continuous and entirely open information flow to and from the publics.

5. Carefully manage information flow to the public in a manner which sheds a positive light on all Cleanup activities.

\section{ARCHITECTURAL SYNTHESIS}

Experience has shown that the public views open and honest communication more favorably than positively managed information flows. In addition recent experience at public meetings has shown that various public groups are interested in and wish to participate in cleanup planning activities. When participation is denied, public distrust builds up. It is also well established that specific issues are of interest to specific groups, such that a uniform approach to all issues is not likely to be efficient. 
A high-performing synthesis alternative for this function should include

(1) provision of a mechanism to allow public participation is the planning and decision processes, (2) maintaining an issues oriented flexible approach for public involvement, and (3) maintenance of a continuous flow of information to and from the public without "spin" management.

\section{SYNTHESIS DEFINITION}

Provide for public participation in the planning and decision processes, maintain an issues oriented flexible approach for public involvement, and maintain a continuous flow of information to and from the public without "spin" management.

\subsubsection{Identify Issues (3.1)}

The IDENTIFY ACTIVITIES MOST MEANINGFUL TO PUBLIC INVOLVEMENT (3.1) function defines areas of high interest to the various public sectors (sometimes called publics).

\section{ALTERNATIVES CONSIDERED}

1. Identify the issues of interest to the publics by utilization of wide ranging input resources including public meetings, the Hanford Advisory Board (HAB), one-on-one interactions, position papers, feedback from program personne1, etc.

2. Brainstorm/strategic planning sessions using in-house staff to set criteria for public interaction.

3. Develop and disseminate an inventory of key issues for self selection by interested public groups.

4. Develop screening criteria which determines the need for Public involvement using in-house expertise; upgrade the criteria using feedback by the public.

\section{ARCHITECTURAL SYNTHESIS}

Issues identification processes which emphasize in-house expertise tend become self-serving or at best myopic. The issues identification processes needs to be based on the public's need to participate in a manner they deem appropriate rather than in a mode defined by cleanup authorities.

The synthesis alternative for this function therefore becomes utilization of wide ranging inputs which indicate where public interest exists and dissemination of a key decision inventory for self-identification of decisions of interest. 


\section{SYNTHESIS DEFINITION}

Analyze broad information resources and seek feedback on key decisions selected by the public from dissemination of key decision inventory data.

\subsubsection{Identify Information Needs For Public Groups}

The IDENTIFY NEEDS (3.2) function defines areas where the cleanup mission needs public involvement.

\section{ALTERNATIVES CONSIDERED}

1. One-on-one contacts with the publics.

2. Indirect information flow from lawsuits, position papers, interviews, briefings, $H A B$.

3. Association with decision inventory feedback from function 3.1 .

4. Brainstorming.

5. Importing methods from high-performing outside organizations.

6. Utilization of IAP3 $^{1}$ as a technical resource for the construction of a specific public involvement plan.

7. Utilize Creighton and Creighton approach to planning public invol vement.

\section{ARCHITECTURAL SYNTHESIS}

All the above listed alternatives have value to the public involvement process with the possible exception of brainstorming. The brainstorming approach will provide an inconsistent approach which depends on the people involved in brainstorming, their familiarity with the issue, and the current environment. A more deliberate process like the creighton and Creighton method is capable of approaching each issue in a flexible manner but with a consistent tool set.

The synthesis alternative consists of using the Creighton ${ }^{2}$ methods and IAP3 information to formulate specific public involvement plans for specific issues, and building an understanding of publics needs through information gathering and self-expressed interest in the inventory lists of function 3.1 .

\footnotetext{
${ }^{1}$ International Association of Public Participation Practitioners.
}

${ }^{2}$ Approach described by J.C. Creighton to WHC Public Involvement organization (undocumented). 


\section{SYNTHESIS DEFINITION}

Use the Creighton and Creighton approach to develop public involvement plans, evaluate public needs by information gathering and self-expressed interest in the Cleanup key decision inventory list (function 3.1)

\subsection{REMEDY UNSAFE AND UNACCEPTABLE CONDITIONS}

The REMEDY UNSAFE AND UNACCEPTABLE CONDITIONS function provides the physical changes needed to complete the function and provides the safe and efficient operation of all facilities. Included within this function are environmental restoration (ER) of buildings, facilities, groundwater, and soils, treatment of waste materials, interim storage of various materials, disposition of low-level waste (LLW), packaging and shipment of hazardous, transuranic (TRU), mixed waste (MW), and high-level waste (HLW), retrieval of wastes for disposition, regulatory compliance actions, and disposition of new imported wastes and materials.

\section{ALTERNATIVES CONSIDERED}

This function is the Keystone of the site cleanup architecture.

1. Focus onty on elimination of environmental contamination events which extend beyond the site boundary and eliminate undesirable discharges to the river.

2. Dispose of all waste materials by shipment of raw or minimally treated waste materials to offsite treatment centers or to approved disposal sites.

3. Conduct a "pristine" cleanup where all lands and natural resources are returned to their natural state and remove all contaminants to offsite disposition.

4. Provide for onsite waste disposition for material classifications which meet applicable environmental requirements and remove the remainder to offsite disposal facilities. Specifically, provide MW, LLW, and unregulated materials disposition on the 200 Area plateau, and remediation of non-200 areas to acceptable and confirmed "end use" requirements.

5. Interim store wastes and materials which are designated for disposition in offsite facilities which are not ready to accept shipment or which are awaiting disposal policy decisions.

6. Use only new facilities and infrastructure to conduct cleanup activities to avoid liabilities associate with old noncompliant installations.

7. Modify existing facilities as necessary to conduct cleanup to reduce contamination spread. Construct new facilities only as a last resort. 


\section{ARCHITECTURAL SYNTHESIS}

The set described above leads to a synthesis which utilizes some alternatives and rejects others. Alternative 1 , while offering significant cost advantage, is inconsistent with public policy (TPA, DOE). Pristine cleanup is rejected on high cost and lack of adequate technology. The preferred synthesis alternative consists of Utilization of the 200 Area plateau for compliant disposal of LLW, MW, and unregulated materials; cleanup to "end use" requirements elsewhere; release of compliant gaseous and aqueous streams to the environment; export of all wastes/materials which must be dispositioned offsite (HLW, TRU, etc.); interim storage of packaged wastes/materials which must be disposed offsite but cannot yet be shipped; utilization of existing facilities where appropriate; acquisition of new facilities/ infrastructure as needed.

The synthesis architecture corresponds closely with the guidance provided in the Hanford Mission Plan, (HMP) (DOE-RL 1994). Offsite disposal of HLW and TRU waste is mandated by national policy. No offsite MW disposal site currently exists therefore disposition onsite must occur or MW must be stored until an offsite option becomes available. In order to allow lower level architectures to be developed, the onsite disposal option will be assumed.

\section{SYNTHESIS DEFINITION}

The Hanford Cleanup System will: utilize the 200 Area plateau for compliant disposal of $L L W, M W$, and unregulated materials; cleanup to "end use" requirements elsewhere, release compliant gaseous and aqueous streams to the environment, export wastes/materials which must be dispositioned offsite (HLW, TRU, etc.); interim store of packaged wastes/ materials which must be disposed offsite but cannot be shipped during mission life; Utilize existing facilities for mission activities where appropriate; acquire new facilities/infrastructure as needed.

\subsubsection{Deactivate Facilities (4.1)}

The DEACTIVATE FACILITIES (4.1) function contains the safe operation of all facilities until further operation is no longer mission essential. The primary output is eventual facility conversion to a state where transfer to the function 4.4 or 5.0 can take place.

\section{ALTERNATIVES CONSIDERED}

1. Place facilities in a safe condition on a risk based priority system which concentrates efforts on high-risk items.

2. Every facility not directly contributing to the mission at this time, for which no future use is confirmed (clearly identified by end user) is to be deactivated.

3. Upgrade facilities as needed to meet potential but unconfirmed future users requirements. 
4. Define deactivation as the state where facilities are stable, present low risk to the follow-on demolition work (function 4.4), and where the expertise associated with facilities operations is no longer needed for final disposition, and where a minimal operations crew can maintain the safety envelop.

5. Deactivation is complete when the demolition organization agrees that turnover meets their requirements.

6. Eliminate physical barriers (i.e., resident sub-missions, inter-facility dependencies, etc.) to deactivation by transfer of "high-risk" equipment and materials to qualified storage or to use by others.

7. El iminate current high risks from unused facilities, minimize maintenance operations, and allow managed degradation until site restoration activities are initiated.

\section{ARCHITECTURAL SYNTHESIS}

Cost and risk involved with running excess facilities can be minimized by expediting the transition to a state requiring low maintenance costs with acceptable risk prior to final disposition. In addition, the expertise needed to place key facilities in the desired configuration is retiring, which will continually diminish corporate memory over the next decade. Deactivation must proceed at a rate sufficient to take advantage of this valuable resource. Speculative investment in facility upgrades is open ended, represents a poor use of government funds, and provides a doubtful rationale for continued facilities operations and should not be continued.

The synthesis alternative for this function consists of a rapid risk based stand down of facilities having no confirmed future use to the point where a stable configuration exists which poses a low risk to follow-on demolition activities. Deactivated facilities will be allowed to degrade in a manageable way until final disposition occurs. Physical barriers to total deactivation will be el iminated by transfer of "highrisk". materials and equipment to qualified waste storage.

\section{SYNTHESIS DEFINITION}

Facilities having no confirmed future use will be rapidly deactivated to the point where a stable configuration exists which poses a low risk to follow-on demolition work. Deactivated facilities will be allowed to degrade in a manageable way until final disposition occurs. "High-Risk" equipment and materials will be transferred to qualified waste storage.

\subsubsection{Deactivate Facilities With Special Nuclear Materials and Nuclear} Materials (Type 1 Facility) (4.1.1). Deactivates facilities containing the following materials: special nuclear materials (SNM), nuclear materials (NM), nuclear fuels (NF) and may include radioactive or hazardous materials (e.g., Plutonium-Uranium Extraction (PUREX) Plant, Plutonium Finishing Plant. 


\section{ALTERNATIVES CONSIDERED}

1. Remove SNM/NM/NF, abandon in place with appropriate reentry security and allow continued degradation which will not interfere with ER final disposition. Dispose of excess materials with net value. All utilities and interties to other facilities are placed in a safe minimum maintenance configuration.

2. Abandon without concern for final disposition. All utilities and interties to other facilities are placed in a safe minimum maintenance configuration.

3. Specify the nature, extent, and location of all radioactive materials, hazardous, and SNM/NM/NF in sufficient detail to allow demolition activities to proceed with acceptable risk to workers, the public, and the environment.

4. Remove radioactive materials and SNM/NM/NF which require facility expertise and capability for retrieval or disposition when such materials pose an unacceptable risk to follow-on demolition activities, or to prevent migration to uncontaminated areas.

\section{ARCHITECTURAL SYNTHESIS}

Type 1 facilities differ from other facilities because they contain SNM, inventoried NM, and NF. Type 1 facilities can be converted to type 2 facilities by removal of the SNM/NM/NF and subsequently be deactivated in similar fashion. The systems architecture must assign SNM/NM/NF removal to function 4.4 or 4.1 . Since 4.7 is directly concerned with handling SNM/NM/NF, and 4.4 is not directly concerned with SNM/NM/NF, removal is assigned to the 4.1 function.

The synthesized alternative therefore consists of portions of 1,3 , and 4, as described for type 2 facilities, with the added requirement of SNM/NM/NF removal prior to demolition turnover. The resulting synthesis architecture for type 1 facilities calls for preparation for turnover demolition by removal of SNM/NM/NF, disposition of radioactive and hazardous materials which require existing or upgraded plant capability prior to turnover to demolition, identification and stabilization of remaining hazardous or radioactive materials before termination of operations to take advantage of resident expertise, risk minimization to public and workers through controlled entry, remove excess materials with a net value and cost minimization by conducting only sufficient maintenance to provide an acceptable condition to demolition workers. Where possible type 1 facilities will have all utilities services and interties to other facilities minimized.

\section{SYNTHESIS DEFINITION}

Identify and stabilize hazardous and radioactive materials, remove radioactive materials which pose a threat to ER work, remove SNM/NM/NF, terminate utilities and facilities interties, provide secure reentry access, abandon facilities except for surveillance and minimize maintenance prior to demolition activities. 
4.4.1.1.1 Maintain Safety and Compliance Envelope (Type 1 Facility) (4.1.1.1). Maintains the facility structure, qualified staff, safe and compliant equipment, documentation and provides assessment of safety and compliance states. Provides all necessary resources for safe and compliant operation in accordance with governing safety codes and regulations.

\section{ALTERNATIVES CONSIDERED}

1. Utilize existing Safety Programs and Documentation. Archive safety and compliance documentation, revise safety and compliance documentation during deactivation, maintain QA.

2. Restrict facility access, perform minimal surveillance and maintenance.

3. Minimize and isolate energy sources.

4. Provide property protection at a level commensurate with actual future use value.

5. Do all reconfiguration using OSHA construction standards rather than OSHA operation requirements.

6. Bound each facility by generic safety and compliance documentation.

7. Fence and restrict facility access and allow degradation.

8. Fine tune the safety documentation commensurate with changing deactivation facility status and associated risks during the deactivation process.

9. Provide inventory and security control of sensitive materials.

\section{ARCHITECTURAL SYNTHESIS}

A high-performance system includes continual reduction of the size of the active safety and security envelope as deactivation takes place. The residual envelope would include the items discussed in 1), 8), and 9). Deactivated areas would be bounded by 2) and 7). Items 4) and 5) would reduce costs while leading to an acceptable deactivation state.

\section{SYNTHESIS DEFINITION}

Only those systems and portions of a facility involved with the size of the active safety and compliance envelop are maintained and operated. All aspects of the safety envelop need to be fine tuned during the deactivation process to reflect the continual reduction in the size of the active safety envelop taking place. All facility reconfigurations are performed under OSHA construction requirements. 
4.4.1.1.2 Determine Deactivation Plans and Negotiate Turnover Endpoint (Type 1 Facility) (4.1.1.2). Assess the current state of the facility, identify and/or negotiate material and equipment disposition requirements, develop plans to deactivate facilities, and negotiate and administratively maintain the desired facility turnover endpoint specifications. Establish and maintain a long-term archive of facility information.

\section{ALTERNATIVES CONSIDERED}

1. Create a bounding deactivation $\mathrm{plan}$ (that would cover most facility issues) in a generic deactivation plan.

2. Deve1op facility-specific deactivations plans.

3. No characterization of facility state is provided (assume it is done by demolition workers, use process knowledge).

4. Verify facility type (implies total characterization of chemical, structural, radiological and other safety hazards.

5. Perform field walk downs to verify facility status.

6. Use facility process knowledge and documentation to establish facility status.

7. Develop facility-specific turnover criteria.

8. Use formal design methodology for configuration control during deactivation.

9. No formal design methodology for configuration control during deactivation.

10. Use a graded approach to design for configuration control during deactivation.

11. Analyze facility categorization for reduction feasibility.

\section{ARCHITECTURAL SYNTHESIS}

In order to insure that deactivation planning is consistent, a bounding plan should be prepared for type 1 facilities in areas common to al1. These bounding plans should be supplemented by facility specific plans. Since long time periods may be expected between deactivation and final disposition, full characterization should be completed while knowledgeable staff is available and records are fresh. Characterization should be based on a combination of existing data, walk downs, and any supplemental work needed for full characterization. However, a graded approach to characterization must be employed to provide focus to highrisk areas and eliminate over-characterization of low risk elements.

Formal design control and configuration management methods will be needed during deactivation to insure safety and to assist in facility characterization. 


\section{SYNTHESIS DEFINITION}

Develop a generic type 1 deactivation plan. Augment the generic plan with facility specific planning. Use formal design and configuration control procedures. Provide the characterization data needed by disposition activities using current knowledge, walk downs, and supplemental investigations. Use a graded approach for characterization.

\subsection{Stabilize and Reconfigure Facilities For Minimum Surveillance} (Type 1 Facility) (4.1.1.3). Deactivates nonessential systems, system components, and physical structures, and takes other actions as required to minimize enyironmental, public, and personnel hazards. Takes these actions consistent with minimizing continuing facility costs.

\section{ALTERNATIVES CONSIDERED}

1. Farm out all or portions of facilities work to private sector (preferred to support the local economy).

2. Perform deactivations in-house.

3. May require isolation of portions of facility.

4. Stabilize and/or prepare specific hazardous waste(s) for packaging and shipping offsite.

5. Stabilize and/or prepare hazardous wastes for transfer to solid waste function (4.3).

6. Stabilize and/or prepare specific radioactive waste(s) for disposition or disposal offsite.

7. Stabilize and/or prepare radioactive material for transfer to solid waste or tank waste functions (4.3 or 4.2$)$.

8. Send SNM, NM, NF to function 4.7 , or dispose of as a waste.

\section{ARCHITECTURAL SYNTHESIS}

Trade studies, the NEPA process, modeling, simulation, and engineering judgement may be used to quantify alternatives. However, a tentative synthesis architecture is as follows.

Convert type 1 facilities to type 2 's as soon as possible, and consolidate SNM/NM/NF materials early in the deactivation process to minimize the size and complexity of the safety and compliance envelop. Type 1 facility personnel should perform any initial stabilization or preparation activities involving SNM/NM/NF materials and radioactive or hazardous waste for disposition either on or offsite, (at least when their expertise, knowledge and/or skills are required to safely disposition these materials). 


\section{SYNTHESIS DEFINITION}

Type 1 facilities will convert to type 2 's as soon as possible. Type 2 facilities will consolidate their SNM/NM/NF materials early in the deactivation process to minimize the size and complexity of the safety and compliance envelop. Type 1 facility personnel will perform any initial stabilization or preparation activities involving SNM/NM/NF materials and radioactive waste for disposition either on or offsite.

4.4.1.1.4 Disposition Currently Identified Radioactive Materials Held As A Potential Product and Special Nuclear Material (Type 1 Facility) (4.1.1.4). Collects and prepares materials for temporary storage and transfer, and transports materials out of the facility.

\section{ALTERNATIVES CONSIDERED}

1. Deactivate facility except for the portion containing SNM/NM/NF, interim store SNM/NM/NF until transfer to 4.7 .

2. Early categorization, consolidation, preparation and disposal of SNM/NM/NF。

3. Delay categorization, consolidation, preparation and disposal of SNM/NM/NF .

4. Obtain a decision by DOE that stored SNM/NM/NF materials are waste.

\section{ARCHITECTURAL SYNTHESIS}

Trade studies, the NEPA process, modeling, simulation, and engineering judgement may be needed to quantify alternatives. However, a tentative synthesis architecture is as follows:

Alternative 1 is essentially an option already chosen for the 308 Building deactivation. The interim storage of SNM/NM/NF has been consolidated into a very small area of the existing building, and only this area has any utility services. This presents a low energy, maintenance, and surveillance cost mode for this facility, until D\&D. Early categorization of the facility and materials usually saves time, enhances worker safety and is more cost effective (especially if early removal is possible, since this allows the facility to become a type 2 instead of the more expensive type 1) than delaying these activities.

The synthesis architecture includes categorization, consolidation and preparation for disposal of SNM/NM/NF material early in the facility deactivation process, and deactivation of all other portions of the facility while maintaining the necessary safety and compliance envelop. 


\section{SYNTHESIS DEFINITION}

Perform the categorization, consolidation and prepare for disposal of SNM/NM/NF material early in the facility deactivation process, and deactivate all other portions of the facility while maintaining the necessary safety and compliance envelope.

\subsubsection{Deactivate Facilities With Radioactive and Hazardous Material} (Type 2 Facility) (4.1.2). Deactivates facilities containing radioactive or hazardous materials, but which do not contain SNM/NM/NF.

\section{ALTERNATIVES CONSIDERED}

1. Deactivate, provide appropriate reentry security, and allow continued degradation which will not interfere with final disposition. All utilities and interties to other facilities are placed in a safe minimum maintenance configuration. Valuable materials are recovered and sent to function 5.0.

2. Abandon without concern for final disposition. All utilities and interties to other facilities are placed in a safe minimum maintenance configuration.

3. Specify the nature, extent, and location of all hazardous or radioactive materials in sufficient detail to allow demolition activities to proceed with acceptable risk to workers, the public, and the environment.

4. Remove radioactive materials which require facility expertise for retrieval or disposition when such materials pose an unacceptable risk to follow-on demolition activities, or to prevent migration to uncontaminated areas.

\section{ARCHITECTURAL SYNTHESIS}

The synthesized alternative consists of portions of 1, 3, and 4. Excess type 2 facilities will be prepared for turnover to demolition by removal and disposition of radioactive and hazardous materials which require existing or upgraded plant capability prior to turnover to ER. Identification and stabilization of remaining hazardous or radioactive materials will also be completed before termination of operations to take advantage of resident expertise. Valuable materials will be transferred to Function 5.0. Risk minimization to public and workers requires that entry to deactivated facilities is controlled. Cost minimization requires conducting only sufficient maintenance to provide an acceptable condition to demolition workers. Where possible type 2 facilities will have all utilities services and interties to other facilities minimized. 
WHC-EP-0779

\section{SYNTHESIS DEFINITION}

Identify and stabilize to an appropriate level, hazardous and radioactive materials; remove radioactive materials which pose an unacceptable risk to ER work, place utilities and facilities interties in a safe minimum maintenance configuration; remove valuable materials, provide secure reentry access; deactivated facilities will not be entered, except for surveillance and minimize maintenance (managed degradation) prior to demolition activities.

\subsection{Maintain Safety and Compliance Envelope (Type 2 Facility)} (4.1.2.1). Assesses and maintains the facility structure and its operations in a safe condition. Maintains a qualified facility staff, and maintain required facility and operating documentation.

\section{ALTERNATIVES CONSIDERED}

1. Archive safety and compliance documentation, revise safety and compliance documentation during deactivation.

2. Restrict facility access, perform minimal surveillance and maintenance.

3. Minimize and isolate energy sources.

4. Provide property protection at a level commensurate with future use value.

5. Do al1 reconfiguration during transition under OSHA requirements. Different requirements exist for operations OSHA and construction OSHA, with the latter preferred due to additional flexibility and less restrictive requirements.

6. Each facility must verify they are bounded by the generic safety and compliance documentation.

7. Fence and restrict facility access and allow degradation.

8. Fine tune the safety documentation commensurate with changing deactivation facility status and associated risks during the deactivation process.

\section{ARCHITECTURAL SYNTHESIS}

Alternatives 1, 2, and 6 are all part of a good company Safety and Compliance program. Studies of safety and compliance strategies for facilities transitioning to D\&D need to be performed.

Only those systems and portions of a facility that are necessary to maintain the safety and compliance envelop during the deactivation process are maintained and operated. A11 aspects of the safety envelop need to be fine tuned during the deactivation process to reflect the continual reduction in the safety envelop taking place. All facility reconfigurations are performed under OSHA construction requirements. 
A high-performance system includes continual reduction of the active safety and security envelope size as deactivation takes place. The residual envelope would include elements 1) and 8). Deactivated areas would include 2) and 7). Items 4 and 5 would reduce cost while leading to an acceptable deactivation state.

\section{SYNTHESIS DEFINITION}

Only those systems and portions of a facility that are necessary to support deactivation and to maintain the safety and compliance envelop during the deactivation process are maintained and operated. AT1 aspects of the safety envelop need to be continually challenged during the deactivation process to reflect the continual reduction in the safety envelop taking place. All facility reconfigurations are performed under OSHA construction requirements.

\subsection{Determine Deactivation $\mathrm{Pl}$ an and Negotiate Turnover Endpoint} (Type 2 Facility) (4.1.2.2). Assesses the current state of the facility, identifies and/or negotiates material, and equipment disposition requirements, develops plans to deactivate facilities, and negotiates and maintains the desired facility turnover endpoint specifications. Establishes and maintains a long-term archive of facility information.

\section{ALTERNATIVES CONSIDERED}

1. Create a bounding deactivation plan (that would cover most of facility issues) in a generic deactivation plan.

2. Develop facility-specific deactivations plans.

3. No characterization of facility state is provided (assume it is done by $\mathrm{D \& D}$, use process knowledge).

4. Verify facility type (implies total characterization of chemical, structural, radiological and other safety hazards).

5. Perform field walk downs to verify facility status.

6. Use facility process knowledge and documentation to establish facility status.

7. Develop facility-specific turnover criteria.

8. Use formal design methodology for configuration control during deactivation.

9. No formal design methodology for configuration control during deactivation.

10. Use a graded approach to design for configuration control during deactivation.

11. Analyze facility categorization for reduction feasibility. 


\section{ARCHITECTURAL SYNTHESIS}

In order to insure that deactivation planning is consistent, a bounding plan should be prepared for all type 2 facilities in areas common to all. These bounding $\mathrm{plans}$ should be supplemented by facility specific plans. Since long time periods may be expected between deactivation and final disposition, full characterization should be completed while knowledgeable staff is available and records are fresh. Characterization should be based on a combination of existing data, walk downs, and any supplemental work needed for full characterization. However, a graded approach to characterization must be employed to provide focus to highrisk areas and eliminate over-characterization of low risk elements. Formal design control and configuration management methods will be needed during deactivation to insure safety and to assist in facility characterization.

\section{SYNTHESIS DEFINITION}

Develop a generic type 2 deactivation $\mathrm{plan}$. Augment the generic $\mathrm{plan}$ with facility specific planning. Use formal design and configuration control procedures. Provide the characterization data needed by disposition activities using current knowledge, walk downs, and supplemental investigations. Use a graded approach for characterization.

\subsection{Stabilize and Reconfigure Facilities For Minimum Surveillance} (Type 2 Facility) (4.1.2.3)。 Deactivates nonessential systems, system components, and physical structures, and takes other actions as required to minimize environmental, public, and personnel hazards. Takes these actions consistent with minimizing continuing facility costs.

\section{ALTERNATIVES CONSIDERED}

1. Farm out all or portions of facilities work to private sector (preferred to support the local economy).

2. Perform deactivations in-house.

3. Isolation of portions of facility.

4. Stabilize and/or prepare specific hazardous waste(s) for packaging and shipping offsite.

5. Stabilize and/or prepare hazardous material for transfer to solid waste function $(4.3)$.

6. Stabilize and/or prepare specific radioactive waste(s) for disposition or disposal offsite.

7. Stabilize and/or prepare radioactive material for transfer to solid waste or tank waste functions $(4.3$ or 4.2$)$. 


\section{ARCHITECTURAL SYNTHESIS}

Trade studies, the NEPA process, modeling or simulation and engineering judgement are necessary to quantify these alternatives. However, type 2 facility personnel should perform any initial stabilization or preparation activities involving radioactive waste for disposition either on or offsite, (at least when their expertise, knowledge and/or skills are required to safely disposition these materials).

\section{SYNTHESIS DEFINITION}

Type 2 facility personnel should perform any initial stabilization or preparation activities involving radioactive waste for disposition either on or offsite.

\subsubsection{Deactivate Facilities With Only Hazardous Material, Including} Asbestos (Type 3 Facility) (4.1.3). Deactivates facilities containing hazardous materials, including asbestos.

\section{ALTERNATIVES CONSIDERED}

1. Deactive facility with appropriate reentry security and allow continued degradation which will not interfere with ER final disposition. All utilities and interties to other facilities are placed in a safe minimum maintenance configuration. Valuable materials are recovered and sent to function 5.0.

2. Abandon without concern for final disposition. All utilities and interties to other facilities are placed in a safe minimum maintenance configuration.

3. Specify the nature, extent, and location of all hazardous materials is sufficient detail to allow ER activities to proceed with acceptable risk to workers, the public, and the environment.

4. Place facility in a condition where hazardous materials will not migrate either inside or outside the facility.

\section{ARCHITECTURAL SYNTHESIS}

Risk minimization to public and workers requires that entry to deactivated facilities is controlled. Cost minimization requires conducting only sufficient maintenance to provide an acceptable condition to demolition workers. Identification and stabilization of hazardous materials will be conducted before turnover to demolition to take advantage of resident expertise.

\section{SYNTHESIS DEFINITION}

Identify and stabilize hazardous materials, place utilities and facilities interties in a safe, minimum maintenance configuration, and provide secure reentry access; deactivated facilities will not be entered, except for surveillance and minimize maintenance (managed degradation) prior to demolition activities. 
4.4.1.3.1 Maintain Safety and Compliance Envelope (Type 3 Facility) (4.1.3.1). Assesses and maintain the facility structure and its operations in a safe condition. Maintains a qualified facility staff, and maintains required facility and operating documentation.

\section{ALTERNATIVES CONSIDERED}

1. Company Safety Programs and Documentation. Archive safety and compliance documentation, revise safety and compliance documentation during deactivation, maintain implied $Q A$.

2. Restrict facility access, perform minimal surveillance and maintenance.

3. Minimize and isolate energy sources.

4. Provide property protection at a level commensurate with actual future use value.

5. Do all reconfiguration during transition under OSHA requirements. Different requirements exist for operations OSHA and construction OSHA, with the latter preferred due to additional flexibility and less restrictive requirements.

6. Each facility must verify they are bounded by the generic safety and compliance documentation.

7. Fence and restrict facility access and allow degradation.

8. Need to fine tune the safety documentation commensurate with changing deactivation facility status and associated risks during the deactivation process.

\section{ARCHITECTURAL SYNTHESIS}

A1ternatives 1, 3, and 6 are all part of a good company Safety and Compliance program. Studies of safety and compliance strategies for facilities transitioning to D\&D need to be performed.

Only those systems and portions of a facility that are necessary to maintain the safety and compliance envelop during the deactivation process are maintained and operated. A11 aspects of the safety envelop need to be fine tuned during the deactivation process to reflect the continual reduction in the safety envelop taking place. All facility reconfigurations must meet OSHA construction safety requirements. Type 3 facilities could have their access restricted, utilities disconnected, and only minimal surveillance and maintenance performed.

\section{SYNTHESIS DEFINITION}

Only those systems and portions of a facility that are necessary to support facility deactivation or to maintain the safety and compliance envelop during the deactivation process are maintained and operated. aspects of the safety envelop need to be continually challenged and 
modified during the deactivation process to reflect the continual reduction in the safety envelop taking place. All facility reconfigurations are performed under OSHA construction requirements. Type 3 facilities have their access restricted, utilities disconnected, and minimal surveillance and maintenance are performed until D\&D.

4.4.1.3.2 Determine Deactivation Plan and Negotiate Turnover Endpoint (Type 3 Facility) (4.1.3.2). Assesses the current state of the facility; identifies and/or negotiates material, and equipment disposition requirements; develops plans to deactivate facilities; and negotiates and maintains the desired facility turnover endpoint specifications. Establishes and maintains a long-term archive of facility information.

\section{ALTERNATIVES CONSIDERED}

1. Create a bounding deactivation plan (that would cover most of facility issues) in a generic deactivation plan.

2. Develop facility-specific deactivations plans.

3. No characterization of facility state (assume it is done by D\&D, use process knowledge).

4. Verify facility type (implies total characterization of chemical, structural, radiological and other safety hazards.

5. Perform field walk downs to verify facility status.

6. Develop facility-specific turnover criteria.

7. Use facility process knowledge and documentation to establish facility status

8. Use formal design methodology for configuration control during deactivation.

9. No formal design methodology for configuration control during deactivation.

10. Use a graded approach to design for configuration control during deactivation.

11. Analyze facility categorization for reduction feasibility.

\section{ARCHITECTURAL SYNTHESIS}

In order to insure that deactivation planning is consistent, a bounding plan should be prepared for all type 3 facilities in areas common to all. These bounding plans should be supplemented by facility specific plans. Since long time periods may be expected between deactivation and final disposition, full characterization should be completed while knowledgeable staff is available and records are fresh. Characterization should be based on a combination of existing data, walk downs, and any supplemental work needed for full characterization. However, a graded 
approach to characterization must be employed to provide focus to highrisk areas and eliminate over-characterization of low risk elements. Formal design control and configuration management methods will be needed during deactivation to insure safety and to assist in facility characterization.

\section{SYNTHESIS DEFINITION}

Develop a generic type 3 deactivation $p 1$ an. Augment the generic plan with facility specific planning. Use formal design and configuration control procedures. Provide the characterization data needed by disposition activities using current knowledge, walk downs, and supplemental investigations. Use a graded approach for characterization.

4.4.1.3.3 Stabilize and Reconfigure Facilities For Minimum Surveillance (Type 3 Facility) (4.1.3.3). Deactivates nonessential systems, system components, and physical structures, and takes other actions as required to minimize environmental, public, and personnel hazards. Takes these actions consistent with minimizing continuing facility costs.

\section{ALTERNATIVES CONSIDERED}

1. Farm out all or portions of facilities work to private sector (preferred to support the local economy).

2. Perform deactivations in-house.

3. Stabilize and/or prepare specific hazardous waste(s) for packaging and shipping offsite.

4. Stabilize and/or prepare hazardous material for transfer to solid waste function (4.3).

\section{ARCHITECTURAL SYNTHESIS}

Utilization of the well qualified private sector to perform deactivation of type 3 facilities has the potential to save time and dollars.

\section{SYNTHESIS DEFINITION}

Utilize the private sector to perform deactivation of type 3 facilities.

\subsubsection{Deactivate Facilities Without Radioactive or Hazardous Material} (Type 4 Facility) (4.1.4). Deactivates facilities without radioactive or hazardous materials. Examples include office buildings, etc.

\section{ALTERNATIVES CONSIDERED}

1. Abandon in place with appropriate reentry security and allow continued degradation which will not interfere with ER final disposition. All utilities and interties to other facilities are $\mathrm{placed}$ in a safe minimum maintenance configuration. 
2. Abandon without concern for final disposition. All utilities and interties to other facilities are placed in a safe minimum maintenance configuration.

\section{ARCHITECTURAL SYNTHESIS}

Risk minimization to public and workers requires that entry to abandon facilities is controlled. Cost minimization requires conducting only sufficient maintenance to provide an acceptable condition to disposal workers.

\section{SYNTHESIS DEFINITION}

Type 4 facilities are to be deactivated by terminating utilities services and facilities interties, limiting reentry, and conducting only that maintenance needed to minimize risk to disposal workers.

4.4.1.4.1 Maintain Safety and Compliance Envelope (Type 4 Facility) (4.1.4.1). Assesses and maintains the facility structure and its operations in a safe condition. Maintains a qualified facility staff, and maintains required facility and operating documentation.

\section{ALTERNATIVES CONSIDERED}

1. Archive safety and compliance documentation, revise safety and compliance documentation during deactivation, maintain implied QA.

2. Restrict facility access, perform minimal surveillance and maintenance.

3. Minimize and isolate energy sources.

4. Provide property protection at a level commensurate with future use value.

5. Do all reconfiguration during transition under OSHA requirements. Different requirements exist for operations OSHA and construction OSHA, with the latter preferred due to additional flexibility and less restrictive requirements.

6. Each facility must verify they are bounded by the generic safety and compliance documentation.

7. Fence and restrict facility access and allow degradation.

8. Need to fine tune the safety documentation commensurate with changing deactivation facility status and associated risks during the deactivation process. 
WHC-EP-0779

\section{ARCHITECTURAL SYNTHESIS}

Alternatives 1,3 , and 6 are a11 part of a good company Safety and Compliance program. Studies of safety and compliance strategies for facilities destined for demolition need to be performed.

Only those systems and portions of a facility that are necessary to maintain the safety and compliance envelop during the deactivation process are maintained and operated. All aspects of the safety envelop need to be continually challenged during the deactivation process to reflect the continual reduction in the safety envelop taking place. All facility reconfigurations are performed under OSHA construction requirements. After deactivation these facilities will have their access restricted, utilities disconnected, and only minimal surveillance and maintenance performed.

\section{SYNTHESIS DEFINITION}

Only those systems and portions of a facility necessary for the safety and compliance envelop are maintained and operated. All aspects of the safety envelop need to be fine tuned during the deactivation process to reflect the continual reduction in the safety envelop taking place. All facility reconfigurations are performed under OSHA construction requirements. Type 4 facilities will have their access restricted, utilities disconnected, and minimal surveillance and maintenance are performed until D\&D.

\subsection{Determine Deactivation Plan and Negotiate Turnover Endpoint} (Type 4 Facility) (4.1.4.2). Assesses the current state of the facility, identifies and/or negotiates material, and equipment disposition requirements, develops plans to deactivate facilities, and negotiates and maintains the desired facility turnover endpoint specifications. Establishes and maintains a long-term archive of facility information.

\section{ALTERNATIVES CONSIDERED}

1. Create a bounding deactivation plan (that would cover most of facility issues) in a generic deactivation plan.

2. Develop facility-specific deactivations plans.

3. No characterization of facility state is provided (assume it is done by D\&D, use process knowledge).

4. Verify facility type (implies total characterization of chemical, structural, radiological and other safety hazards).

5. Perform field walk downs to verify facility status.

6. Use facility process knowledge and documentation to establish facility status.

7. Develop facility-specific turnover criteria. 
8. Use formal design methodology for configuration control during deactivation.

9. No formal design methodology for configuration control during deactivation.

10. Use a graded approach to design for configuration control during deactivation.

11. Analyze facility categorization for reduction feasibility.

\section{ARCHITECTURAL SYNTHESIS}

In order to insure that deactivation planning is consistent, a bounding plan should be prepared for all type 4 facilities in areas common to al1. These bounding plans should be supplemented by facility specific plans. Since long time periods may be expected between deactivation and final disposition, full characterization should be completed while knowledgeable staff is available and records are fresh. Characterization should be based on a combination of existing data, walk downs, and any supplemental work needed for full characterization. However, a graded approach to characterization must be employed to provide focus to highrisk areas and eliminate over-characterization of low risk elements. Formal design control and configuration management methods will be needed during deactivation to insure safety and to assist in facility characterization.

\section{SYNTHESIS DEFINITION}

Develop a generic type 4 deactivation plan. Augment the generic plan with facility specific planning. Use formal design and configuration control procedures. Provide the characterization data needed by disposition activities using current knowledge, walk downs, and supplemental investigations. Use a graded approach for characterization.

\subsection{Stabilize and Reconfigure Facilities For Minimum Surveillance} (Type 4 Facility) (4.1.4.3). Deactivates nonessential systems, system components, and physical structures, and takes other actions as required to minimize environmental, public, and personnel hazards. Takes these actions consistent with minimizing continuing facility costs.

\section{ALTERNATIVES CONSIDERED}

1. Farm out all or portions of facilities work to private sector (preferred to support the local economy).

2. Perform deactivations in-house.

\section{ARCHITECTURAL SYNTHESIS}

Utilization of the experienced and qualified private sector to perform deactivation of type 4 facilities is appropriate. Deactivation of uncontaminated structures is not a high-productivity application of Hanford expertise. 


\section{SYNTHESIS DEFINITION}

Utilize the private sector to perform deactivation of type 4 facilities.

\subsubsection{Remediate Tank Waste (4.2)}

Store, treat, and immobilize highly radioactive Hanford waste (existing and future tank waste and the strontium and cesium capsules) in an environmentally sound, safe, and cost effective manner.

\section{ALTERNATIVES CONSIDERED}

Alternatives for "Remediate Tank Waste" have been included in this document from the Tank Waste Remediation System (TWRS) Functions and Requirements document (DOE-RL 1993) for completeness.

Because the physical system is partially established by the present existence of facilities and equipment, physical facilities and equipment alternatives for accomplishing the. TWRS mission were not evaluated. Evaluation of alternative upgrades, new facilities, and equipment for accomplishing the selected TWRS mission will be evaluated at the appropriate lower level architectures. Alternative strategies for accomplishing the TWRS mission were evaluated to establish lower level functions and requirements.

Top level alternatives include:

1. Remove waste from all tanks - Retrieval of most of the waste from the 177 single-she11 tanks (SST) and double-shell tanks (DST), 51 catch tanks and miscellaneous facilities for processing and immobilization. The amount of residual waste acceptable to be left in the tanks will be determined through the development of closure requirements, negotiation with governmental agencies

(e.g., U.S. Nuclear Regulatory Commission [NRC], Washington State Department of Ecology [Ecology], U.S. Environmental Protection Agency [EPA], Yakama Indian Nation), and preparation of necessary NEPA documentation.

2. Dispose of all waste in situ - Leave the waste in the tanks and immobilize the waste in place as necessary to support closure requirements. The final waste form in the tanks will be determined through the development of closure requirements, negotiation with governmental agencies (e.g., NRC, Ecology, EPA, Yakama Indian Nation), and preparation of necessary NEPA documentation.

3. Remove some of the waste from the tanks, in situ dispose the remainder - Remove some of the waste from the tanks and dispose of the remaining waste in place. The selection of tank wastes for retrieval and the amount of residual waste acceptable to be left in the tanks will be determined through the development of closure requirements, negotiation with governmental agencies (e.g., NRC, Ecology, EPA, Yakama Indian Nation), and preparation of necessary NEPA documentation. 
4. Do nothing - Continue to store the waste in the existing tank system indefinitely. Upgrade the storage system as necessary to ensure safe containment of the waste.

\section{ARCHITECTURAL SYNTHESIS}

TPA milestone M-45 specifies removal of all waste in SST's to specified values. The HDWEIS prescribes removal of all waste in DST's.

\section{SYNTHESIS DEFINITION}

Remove all waste from all tanks for subsequent immobilization and disposal.

\subsubsection{Manage Tank Waste (MTW) (4.2.1). Manage existing tank waste} (e.g., waste contained in DSTs, SSTs, and miscellaneous tanks), new tank waste from site level interfaces (e.g., facility operations, D\&D, ER), and in-process waste (e.g.g pretreated HLW, pretreated LLW, partially pretreated waste) from TWRS. Manage tank waste includes safe compliant storage, waste characterization, waste retrieval, waste concentration, and waste transfer to other facilities or processes.

The waste will continue to be managed until all of the waste is removed from al1 of the tanks.

\section{ALTERNATIVES CONSIDERED}

At this level, a single strategy was considered appropriate to comply with requirements allocated to this system rather than consider alternative physical concepts. A detailed description of all the architectural concepts cannot be prepared until the functional decomposition has progressed to a much lower level of detail. Alternative upgrades, new facilities and equipment for accomplishing the mission of the Tank Waste System will be evaluated and described at the appropriate lower level architectures.

The specific strategy considered for satisfying the "Manage Tank Waste" function, subject to all its requirements, involves upgrading existing elements of the Tank Waste System that will be used with the preferred alternative architectures or those that must remain operational for an extended period of time until replaced, or deactivated, to a condition that complies with current codes, regulations, and DOE Orders.

\section{ARCHITECTURAL SYNTHESIS}

none - single alternative

\section{SYNTHESIS DEFINITION}

Safety documentation for the existing systems identify the physical attributes of each system to insure the public and worker safety. Interim Safety Basis documentation identifies the specific upgrades to SSTS and DSTs to insure the pub7ic and worker safety where formal Safety Analysis Reports have not been updated to current standards. 
An evaluation of upgrades required to achieve safe management of tank wastes is presented in WHC-EP-0392, Tank Farm Restoration and Upgrade Program Plan upgrade projects based on risks created by current conditions. Upgrades will be accomplished using a phased approach to compliance, which balances costs with the associated risks and benefits in order to achieve compliance with the applicable environmental, safety, and health standards established by Federal, State, and local 1aws; DOE Orders; and Hanford Site requirements. Agreements negotiated in the TPA (M-43): establish a major milestone for completion of upgrades and associated interim milestones for tank ventilation, instrumentation, electrical, and transfer system upgrades.

Relaxation of any constraint negating or limiting the need for upgrades will be based on documented compliance decisions made by government officials and regulating agencies as appropriate.

Safety documentation covering the existing portion of the Waste Storage System are as follows:

- WHC-SD-WM-SIB-001, Vol. 1, Hanford Site Tank Farm Facility Interim Safety Basis.

- WHC-SD-WM-SAR-023, 242A Evaporator/Crystallizer Safety Analysis Report.

- WHC-SD-WM-SAR-005, Waste Encapsulation Storage Facility Safety Analysis Report.

4.4.2.1.1 Store Waste (4.2.1.1). Contain and monitor SST waste, waste in miscellaneous tanks, and cesium and strontium capsules. Receive, contain, and monitor DST waste and in-process waste. Define and initiate actions for mitigation/resolution of safety issues. Waste is currently being received, contained, and monitored. This will continue until all waste is removed for final processing.

\section{ALTERNATIVES CONSIDERED}

1. The following alternatives were considered for providing adequate DST storage space to support likely operational scenarios:

1a. Build new DSTs - Build enough DSTs to support likely operational scenarios. This includes the future retrieval of SST waste, and new tank waste generated by activities outside of TWRS.

1b. Consolidate waste (blending, volume reduction) - Consolidate the waste by blending and concentration (architecture 4.2.1.5) to make enough tank space available, without new DSTs, to support likely operational scenarios.

1c. Alternative storage methods - Develop alternative storage methods other than liquid waste storage in large underground storage tanks (USTs). 
1d. Local treatment by generators - Aggressively manage tank space by not accepting any new tank waste from other site mission areas.

1e. Consolidate the tank waste and build new DSTs - Consolidate the waste by blending (where practical and the waste is compatible) and concentration to make as much DST tank space available as practical. When necessary, build new DSTs to support likely operational scenarios.

2. The following alternatives were considered for storage of SST waste.

2a. Seal the SSTs until retrieval - Seal all risers, pits, and ventilation systems until the SST waste is retrieved for processing, transfer to an appropriate DST, or resolution of a safety issue. There would only be minimal monitoring of the SSTs.

2b. Continue current storage operations and plans for SSTs Continue to store waste in SSTs until it is needed for processing, resolution of safety issues, or appropriate space is available in the DSTs. This would include any practical upgrades to waste maintenance or monitoring equipment that would ensure safe storage, but would not include any major overhauls of the SST storage system.

2c. Perform major overhaul of SST storage system - Upgrade all waste maintenance and monitoring equipment in the SST storage system. This would provide for long-term storage in the SSTs until the waste was removed for processing.

3. The following alternatives were considered for storage of miscellaneous underground storage tank (MUST) waste.

3a. Actively store MUST waste in place - Continue to store MUST waste in place until it is needed for processing, resolution of safety issues, or appropriate space is available in the DSTs. This would include any upgrades to waste maintenance or monitoring equipment that would ensure safe storage.

3b. Do nothing with MUSTS - Do not perform any upgrades on the MUSTs, and perform only minimal monitoring until the MUST waste can be retrieved for processing, resolution of a safety issue, or transfer into appropriate DST storage.

3c. Immediately remove waste from MUST storage - Remove waste from MUSTs as quickly as possible and store in DSTs.

4. The following alternatives were considered for storage of cesium and strontium capsules.

4a. Store cesium and strontium capsules in new "wet" storage facility - Build a new "wet" storage facility to store the cesium and strontium capsules. 
4b. Store cesium and strontium capsules in new "dry" storage facility - Build a new "dry" storage facility to store the cesium and strontium capsules.

4c. Continue storing cesium and strontium capsules in the Waste Encapsulation Storage Facility (WESF) - Continue to store the cesium and strontium capsules in the pool cells at WESF, making any necessary upgrades to ensure safe storage, until the capsules are retrieved for processing.

\section{ARCHITECTURAL SYNTHESIS}

Continue to store waste in SSTs until it is needed for processing, resolution of safety issues, or appropriate space is available in the DSTs. This includes any practical upgrades to waste maintenance or monitoring equipment that would ensure safe storage, but would not include any major overhauls of the SST storage system.

This option will provide acceptable SST waste storage ensuring safe storage until the waste can be retrieved. The option of sealing the SSTs was not considered compliant with safe storage requirements, and it was not considered plausible or cost effective to perform a system wide overhaul (alternative 2c). An evaluation of upgrades to achieve safe, compliant storage is presented in WHC-EP-0392, Tank Farms Restoration and Upgrades Program Plan. The Status Report on Resolution of Waste Tank Safety Issues at the Hanford Site (WHC-EP-0600), and the Hanford Site Tank Waste Remediation System Technical Strategy, Rev.0, document, and the Hanford Federal Facility Agreement and Consent Order (TPA) offer support for this decision. Specific architectural details are given in TPA $M-40, M-41$, and $M-42$.

\section{SYNTHESIS DEFINITION}

Continue storage until waste is needed for processing, improve system to achieve safe TPA (M-40) and compliant storage TPA (M-4I), and construct additional tanks as needed TPA (M-42).

4.4.2.1.2 Characterize Waste (4.2.1.2). Provide physical, chemical, and radiological characterization information in support of process control, safety issue resolution, treatment, storage, or disposal (TSD) decisions, or other TWRS needs. Waste characterization activities include sample acquisition and transfer to laboratory, laboratory analys is of samples, performance of in situ measurements, and review of historical data and $1 a b$ results as necessary to complete characterization.

Waste characterization is currently being performed and will continue until the waste is retrieved and the waste tanks meet the Manage Systems Generate Waste and Excess Facilities acceptance criteria.

\section{ALTERNATIVES CONSIDERED}

At this level the alternatives considered for the characterization of tank wastes resemble alternative processes that can be applied to any given source of tank waste rather than alternative physical systems. 
A detailed description of the architectural concepts cannot be prepared until the functional decomposition has progressed to a much lower level of detail. Alternative upgrades, new facilities and equipment for accomplishing the mission of the Waste Characterization System will be evaluated and described at the appropriate lower level architectures.

The specific processes considered for satisfying the "Characterize Waste" function subject to all its requirements are as follows:

1. Use existing waste characterization information.

2. Obtain and analyze waste samples.

3. Perform analyses of waste in situ:

\section{ARCHITECTURAL SYNTHESIS}

All three alternatives above will be used to characterize waste. In some cases, existing information such as previous sampling and analysis results, process flowsheet information, and tank transfer records may provide sufficient information to meet some characterization needs. In most cases, additional information will be needed. Sampling and analysis is the best means for collecting many of the chemical, radiochemical, and physical properties that must be known about the wastes. In situ analysis will provide selected analyses on the wastes in the actual waste environment. Certain analyses (such as shear strength) can provide more realistic results because the "samples" have not been disturbed by removal to a laboratory. In addition, these techniques have the potential to provide certain information more efficiently (at a lower cost, with less exposure, and/or more quickly) than sampling and analysis. The Tank Waste Remediation System Characterization Technology Development Plan, WHC-SD-WM-PLN-053, Rev. 0, specifies development of new analytical as we11 as in situ methods for characterizing wastes.

\section{SYNTHESIS DEFINITION}

Use existing waste information and provide new data as needed to develop process flowsheets and to meet TPA (M-44) milestones.

4.4.2.1.3 Retrieve Waste (4.2.1.3). Remove tank waste from SSTs, DSTs, and miscellaneous tanks, and remove the cesium and strontium capsules from storage for transfer to other facilities. Wastes to be removed from the tanks include liquids, saltcake, sludges, slurries, and solids (e.g., failed equipment, concrete, rocks, lead bricks, samarium balls, and cobalt slugs). Solids will be removed only to the extent necessary to prevent interference with the retrieval of other wastes or as required to complete closure activities.

Waste retrieval has been initiated. Sufficient waste will be removed to allow closure without further removal of material. 


\section{ALTERNATIVES CONSIDERED}

The alternatives considered for the waste retrieval system are generalized process alternatives or strategies. Retrieval systems alternatives are considered by mobilization process and the platform for positioning the equipment. Several alternatives may be required depending on the storage facility type (SST, DST, MUST, and WESF pool cells), physical condition and congestion, and waste types. More specific processes and platforms will be selected for each type tank at the next level of functional decomposition.

\section{Mobilization Processes}

1a. Mechanical Retrieval. Processes - Mechanical retrieval systems use mechanical force to dislodge or mobilize waste solids so they can be removed from the tank. These systems include, but are not limited to those that use mechanical scraping or impacting to breakup or dislodge the waste. Such systems normally require a stiff, stable base. Designs using momentum, electromagnets, or other technologies could permit the use of less stable bases. Cs/Sr capsules are currently retrieved with manually operated tongs and manipulators.

1b. Hydraulic Retrieval Processes - Hydraul ic retrieval systems use high-velocity hydraulic jets or streams to mobilize the waste. These systems include, but are nor limited to mixer pumps, unlimited sluicing, limited sluicing, confined sluicing to generate high-velocity streams or jets impacting the waste to dislodge, dissolve, or slurry the waste. Hydraulic jet nozzles for most sluicing systems do not have to be very close to the waste surface to be effective. Rapid atomization, however, requires that ultra-high pressure sluicing nozzles must be very close to the waste surface.

1c. Pneumatic Retrieval Processes - Pneumatic retrieval systems use a high-velocity pneumatic jets to mobilize the waste.

Pneumatic jets dissipate rapidly and, thus, must be close to the waste surface to be effective.

Id. Dissolution Processes - Dissolution systems use water or other chemicals to dissolve waste.

le. Thermal Processes - Thermal systems are use temperatures increases or changes to mobilize the waste. These systems include, but are not limited to systems that use phase changes to liquify or vaporize the waste, use heat to turn the waste into a powder, and use thermal stresses developed by rapid temperature changes do breakup the waste.

1f. Focused UItrasonic Processes - Focused ultrasonic systems use directed ultrasonic waves to breakup or dislodge waste for movement to a conveyance system. 
1g. Shaped Processes - Shaped charge systems use small shaped explosive charges to dislodge waste for movement to the conveyance system.

\section{Positioning Platforms}

2a. Dome Mounted - Dome mounted process equipment movement is inserted through a riser with movement limited to elevation and rotational changes directly below the risers. This platform cannot position the retrieval equipment close to the waste being retrieved.

2b. Overhead Crane - Retrieval equipment can be mounted to an overhead crane with nearly unlimited vertical, horizontal, and rotation movement. Equipment access to waste in the USTs would require a large opening in the top of the tanks. No modifications would be required for access to the $\mathrm{Cs}$ and $\mathrm{Sr}$ capsules.

2c. Robotic Arm - Robotic arm mounted process equipment movement includes vertical, horizontal, and rotational changes. It can position the retrieval equipment close to the waste being retrieved.

2d. Robotic Vehicle-Robotic vehicle mounted process equipment is limited by the vehicles ability to move across the tank and waste surfaces. It can position the retrieval equipment close to the waste being retrieved as long as it can maneuver across the tank or waste surfaces.

\section{ARCHITECTURAL SYNTHESIS}

Combination of Mechanical and Hydraulic Retrieval Processes - These processes have been selected by previous engineering studies for retrieving SST and DST waste (WHC-SD-WM-252, Rev. 0 , and WHC-SD-WM-TI-593, Rev. 0). It is assumed that the same processes will be applicable for retrieving waste in the MUSTs. The existing Cs/Sr capsule handling system is a mechanical system. The specific process will depend on the type and condition of the storage facility and the type of waste being retrieved.

Dome mounted and robotic arm platforms have been selected by previous engineering studies (WHC-SD-WM-252, Rev. 0, and WHC-SD-WM-TI-593, Rev。0) for positioning retrieval equipment in the USTs. It is assumed that the same platforms will be applicable for retrieving waste from the MUSTs. Specific platforms will be selected depending on the process being used, the type and condition of the storage tank and the type of waste being retrieved. 


\section{SYNTHESIS DEFINITION}

A combination of mechanical and hydraulic processes will be used for retrieval. Dome mounted and robotic arm combinations will be used for positioning retrieval mechanisms. Additional retrieval specifications are provided in TPA M-45.

4.4.2.1.4 Transfer Waste (4.2.1.4). Move retrieved liquid, slurry, and solid tank waste from SSTs, DSTs, miscellaneous tanks, and the cesium and strontium capsules from WESF to treatment facilities or other storage locations. Move new tank waste from facilities outside of TWRS to treatment facilities or to storage. This function does not encompass waste sample transfers, transfers within treatment facilities, or transfers to and from the evaporator, but does include the transfers of in-process waste and transfers of secondary waste.

This will continue until all waste is transferred from the tanks.

\section{ALTERNATIVES CONSIDERED}

At this level, the alternatives considered for the transfer of tank wastes resemble various processes that can be applied given the distance, quantity, and physical characteristics of the waste to be transferred. A detailed description of all the architectural concepts cannot be prepared until the functional decomposition has progressed to lower levels of detail. Alternative upgrades, new facilities and equipment for accomplishing the mission of the Waste Transfer System will be evaluated and described at the appropriate lower level architecture.

The specific processes considered for satisfying the "Transfer Waste" function subject to all its requirements are as follows:

1. Transfer Lines - Transfer of tank waste as slurry or supernate through an underground piping system.

2. Tanker Vehicle - Transfer of tank waste as slurry or supernate by transport vehicle.

3. Shielded Cask - Transfer of capsules and other unique sources (e.g., cobalt slugs and fuel pins presently contained in a few SSTs) by shielded cask carried by transport vehicle.

4. Solid Waste Container - Transfer of solid tank waste (e.g., sludges and saltcakes) in containers carried by transport vehicles prior to conversion to slurry required for processing by the Waste Processing System.

5. Pneumatic Transfer - Pneumatic transfer of capsules from WESF to a process facility provided by the Process Waste System. 


\section{ARCHITECTURAL SYNTHESIS}

Transfer lines, tanker vehicles, shielded casks, and containers are currently employed as methods of waste transfer. Deployment of any one alternative or combination of alternatives will be dependent on distance, quantity and physical characteristics of the waste to be transferred.

\section{SYNTHESIS DEFINITION}

Transfer approach will depend on the detailed requirements of a specific transfer problem. No choice is ruled out at this point.

4.4.2.1.5 Concentrate Waste (4.2.1.5). Remove excess water from 1iquid DST waste to reduce volume of waste feed for immobilization and to free up storage capacity in existing tanks.

\section{ALTERNATIVES CONSIDERED}

At this level the alternatives considered for the concentration of tank wastes resemble alternative processes rather than specific physical systems with the exception of the evaporation alternative, which is embodied in an existing facility. A detailed description of the architectural concepts involving specific equipment will be prepared as the functional decomposition progresses to lower levels.

1. Manage tank farm storage space without concentration of tank waste This would require the construction of additional tanks to store wastes until a significant volume of tank waste has been immobilized freeing up existing DSTs. The burden of excess water removal would be shifted to the pretreatment and immobilizing waste processes.

2. Evaporation - Separate the liquid fraction by applying heat to the waste and collecting the water vapor generated from the evaporation process.

The existing 242-A Evaporator/Crystallizer implements this process. Project B-534 has upgraded the evaporator resulting in a planned life extension of 10 years.

3. Selective Precipitation - Selective precipitation of radionuclides and/or hazardous materials to allow separation of a liquid fraction.

4. Reverse osmosis - Separate particulate and dissolved solids from water by forcing the water though multiple stages of membranes at a pressure greater than the osmotic pressure of water.

5. Ion exchange - Ion exchange separation of radionuclides and/or hazardous materials.

6. Crystallization - Crystallize the nonradioactive components and separate these components for treatment and disposal. Store the radioactive components for pretreatment. 


\section{ARCHITECTURAL SYNTHESIS}

None needed at this level.

\section{SYNTHESIS DEFINITION}

Remove excess water from tank wastes of sufficient purity to be treated as an liquid effluent for eventual discharge to the environment. The concentrated tank waste as a product of this process will remain pumpable without dilution when returned to the DSTs for storage.

Specifically, the Waste Concentration System is comprised of the existing facility known as the 242-A Evaporator/Crystallizer.

\subsubsection{Process Waste $(4.2 .2)$. Pretreat tank waste (including DST and SST} waste, line waste, and cesium and strontium capsules, if required) to separate the LLW, HLW, and TRU waste, and reusable materials fractions; immobilize the HLW and TRU waste fractions; and certify the immobilized wastes for disposal in a geologic repository. This includes interim storage of and load out capability for the immobilized HLW and TRU waste prior to offsite shipment. Waste excluded from processing is the USTs and support structures, production reactor fuel, radioactive waste at reactors, disposal facilities, transfer lines, and cribs, ponds, and ditches.

The Process Waste function is initiated upon waste retrieval for treatment and will continue until the last immobilized high-level waste/immobilized transuranic waste (IHLW)/(ITRU) package is shipped to a geologic repository.

\section{ALTERNATIVES CONSIDERED}

At this level the alternatives considered for waste processing are related to disposal strategies and processes as opposed to physical systems. A detailed description of the Waste Processing System architecture cannot be prepared until the functional decomposition has been developed to a lower level of detail. The following disposal strategies were investigated:

1. Separate waste into fractions - Pretreat the tank waste into high-level, low-level, and TRU fractions. Cesium and strontium capsules are already separated from the tank waste and are stored in WESF. Immobilize the cesium and strontium capsules, high-level, and TRU fractions for shipment offsite to an approved radioactive waste repository.

2. Immobilize all waste for offsite disposal - Immobilize all of the tank waste without any fractionization, for shipment offsite to an approved radioactive waste repository. 
3. Treat tank waste to intermediate waste form for later immobilization and disposal - Retrieve the tank waste and convert it into a more stable intermediate form for storage while developing technology(ies) for separations and immobilization.

\section{ARCHITECTURAL SYNTHESIS}

The TPA (Hanford Federal Facility Agreement and Consent Order, Fourth Amendment, January $1994 \mathrm{M}-50$ ) is based on the separation of waste into fractions for immobilization and disposal.

The rationale for this strategy is detailed in WHC-EP-0617, Rev. 0, Tank Waste Decision Analysis Report, March 1993.

\section{SYNTHESIS DEFINITION}

Separate tank waste into high and low level fractions.

4.4.2.2.1 Pretreat Waste (4.2.2.1). Separate tank waste into a HLW/TRU fraction and $L L W$ fractions suitable for immobilization and into a fraction suitable for reuse. Pretreatment includes: preparing all retrieved tank waste for separations processes, separating the waste constituents suitable for immobilization as $L L W$ and for reuse, and converting the remaining waste into feeds to the HLW and TRU waste immobilization system. Tank waste will be pretreated when needed to: provide feed for LLW immobilization and/or provide feed for HLW and TRU immobilization.

Pretreatment will continue until all tank waste has been converted to feed for immobilization processes.

\section{ALTERNATIVES CONSIDERED}

At this level the alternatives considered for pretreating the waste are strategies and processes as opposed to physical systems. A detailed description of the Pretreatment System architecture cannot be prepared until the functional decomposition has been developed to a lower level of detail. Common to all alternatives is the capability for appropriate blending, fractionation, and concentration of waste. The following alternatives were considered:

1. Minimum Separation - Utilize existing and new resources and processes to pretreat tank waste to the extent necessary to remove radionuclides from 1 iquid fraction to meet $L L W$ requirements.

2. Remove nonradionuclide components from solid fraction to result in a reasonable quantity of HLW transferred to the geologic repository. Candidate processes are those, such as water washing, caustic washing, selective leaching, ion exchange, precipitation, etc., which do not require complex processing systems and which can be implemented within tanks or relatively simple facilities. 


\section{ARCHITECTURAL SYNTHESIS}

Pretreatment Alternative 1 selected - Minimum Separation

Architecture selection considered the diversity of required pretreatment system products meeting the feed specification for LLW immobilization, the feed specifications for HLW/TRU waste immobilization, and the specifications for reusable materials (recovered bulk chemicals and water). This selection strategy is embodied in the revised TPA (Hanford Federal Facility Agreement and Consent Order, Fourth Amendment, January $1994 \mathrm{M}-50$ ). Known pretreatment processes that have been under study in recent years included TRUEX, CLEAN, CLEAN SALT, ENHANCED SLUDGE WASH, and related options. Evaluation of these pretreatment processes using TWRS performance measures were conducted (WHC-EP-0617, Johnson, 1993). The Minimum Separations alternative was favored in reviews by TWRS program staff, external technical review groups, and stakeholders. The strategies and milestones outlined in the TPA reflect the favorable performance of the Minimum Separations alternative using stakeholder performance criteria. Extending the pretreatment processing necessary to accomplish Alternative 2 was considered to require more resources and risk than practical.

\section{SYNTHESIS DEFINITION}

Pretreat tank waste by separation into a HL/TRU fraction, using the enhanced sludge wash process.

4.4.2.2.2 Immobilize HLW/TRU Waste (4.2.2.2). Immobilize pretreated HLW and TRU waste, seal the immobilized waste into primary containers, decontaminate the container outer surfaces, and test the integrity of the sealed containers.

Tank waste immobilization will begin when the immobilization facility is authorized to begin hot operations and will continue until all of the HLW/TRU is immobilized.

NOTE: DOE/Waste Isolation Pilot Plant (WIPP) requirements apply only if a decision is made to dispose of ITRU at WIPP.

\section{ALTERNATIVES CONSIDERED}

The following processing alternatives were investigated:

1. Vitrification - Immobilize HLW by incorporating it into a glass matrix.

2. Ceramics Manufacture - Immobilization by incorporation of the waste streams into a ceramic matrix.

3. Waste Calcination - Immobilization by converting the tank waste to a powder that will be loaded into a self-shielded cask for storage. 


\section{ARCHITECTURAL SYNTHESIS}

Vitrification as borosilicate glass is selected. The rationale for this assumption is detailed in DOE/RL-90-27, Rev. 1, Evaluation and Selection of Borosilicate Glass as the Waste Form for the Hanford High-Level Radioactive Waste. In addition the TPA M-51 identifies vitrification as the immobilization process with borosilicate glass as the waste form.

\section{SYNTHESIS DEFINITION}

Immobilize the HLW/TRU fraction in borosilicate glass.

4.4.2.2.3 Prepare Cesium and Strontium Capsules for Disposal (4.2.2.3). Receive cesium and strontium capsules from storage, prepare capsules for interim storage at the Hanford Site and disposal offsite at HLW geologic repository.

\section{ALTERNATIVES CONSIDERED}

The following alternatives were considered:

1. No Action - Leave the capsules in place in the WESF pool for extended underwater storage.

2. Remove/Process capsule contents - Remove the capsules from underwater storage, cut open the capsules to remove the contents for blending with remaining tank waste for vitrification and disposal at a geologic repository.

3. Leave capsules intact, place in overpacks appropriate for disposal in the geologic repository - Remove capsules from current storage pools and overpack into containers that meet HLW geologic repository acceptance criteria. Place overpacked containers into a new interim storage facility.

4. Leave capsules intact, incorporate in glass within canisters.

\section{ARCHITECTURAL SYNTHESIS}

Remove capsules from current storage pools and overpack into containers that meet HLW geologic repository acceptance criteria. Place overpacked containers into a new interim storage facility.

The DOE addressed disposition of tank waste (and other radioactive waste at the Hanford Site) in a series of documents that culminated with the "Final Environmental Impact Statement for the Disposal of Hanford Defense, High-Leve1, Transuranic, and Tank Wastes, Hanford Site, Richland, Washington; (HDW-EIS) Record of Decision (53 FR 12449)." The record of decision directs the disposal of cesium and strontium capsules in a geologic repository. 


\section{SYNTHESIS DEFINITION}

Dispose of Cs and Sr capsules in an overpack appropriate for disposal in a geologic repository. Interim store overpacked capsules in an interim storage facility.

4.4.2.2.4 Interim Store IHLW (4.2.2.4). Transport sealed canisters of IHLW from the HLW/TRU Immobilization facility location, emplace IHLW canisters in their designated storage locations, monitor canisters for storage containment integrity, and eventualiy retrieve from storage, prepare, and load IHLW canisters on other transport conveyances for offsite shipment.

The IHLW canisters will be received from the HLW/TRU Immobilization facility on a regular basis, daily or every so many days depending on canister size, glass production rate, and scheduled production run and will continue until a $11 \mathrm{HLW}$ has been immobilized. Accumulation of IHLW canisters in interim onsite storage will continue until a geologic repository is readied and authorizes shipment of IHLW canisters to it at which time dispatch of IHLW canisters will commence and continue on a regular basis until the IHLW facility is emptied of IHLW canisters.

Transport overpacked containers of cesium and strontium from overpacking facility, emplace containers in their designated storage locations, monitor containers for storage containment integrity, and eventually retrieve from storage, prepare, and load containers on other transport conveyances for offsite shipment.

\section{ALTERNATIVES CONSIDERED}

1. Facility Configuration

a. Enclosed facility - Utilize an enclosed facility to provide containment and shielding for the immobilized HLW containers.

b. Open facilities - Utilize exposed storage (e.g., Resource Conservation and Recovery Act [RCRA] compliant pads) for interim storage of IHLW. Shielding provided by external means.

2. Container Configuration

a. Unshielded Containers - Store the IHLW as exposed containers with shielding provided by external means.

b. Large $\left(10 \mathrm{~m}^{3}\right)$ Self-shielded Containers - Store the IHLW containers within self-shielded containers.

\section{ARCHITECTURAL SYNTHESIS}

Facility Configuration - No decision has been made on facility configuration. Further analyses will determine inputs to decision process.

Container Configuration: Alternative $2 \mathrm{~b}$ selected - Large (10 m3) Self-shielded containers. 
The revised TPA (Hanford Federal Facility Agreement and Consent Order, Fourth Amendment, January 1994) is based on the utilization of large (10 m3) self-shielded casks for IHLW.

\section{SYNTHESIS DEFINITION}

See above.

4.4.2.3 Manage System Generated Waste and Excess Facilities (4.2.3). Manage waste and excess facilities generated during the process of remediating TWRS tank waste. Activities to be managed include immobilization of the LLW components, disposition of liquid and gaseous effluent, as well as solid waste and excess facilities, and the recycling of reusable materials.

This effort includes management of miscellaneous wastes and processing to transfer failed equipment like pumps and melters to the organization responsible for ultimate disposal. This activity will terminate when all tank waste is remediated and all excess facilities have been turned over to the site-level Deactivate Facilities function $(4.1)$ for final clean-up and closure.

\section{ALTERNATIVES CONSIDERED}

At this level, the alternatives considered for dealing with the waste and excess facilities generated during the process of remediating the tank waste system resemble alternative strategic concepts rather than alternative physical systems. A detailed description of all the architectural concepts cannot be prepared until the functional decomposition has progressed to a much lower level of detail. Alternative upgrades, new facilities and equipment for accomplishing the TWRS mission will be evaluated and described at the appropriate lower level architectures.

The specific strategies considered for satisfying the "Manage System Generated Waste and Excess Facilities" function are as follows:

1. No treatment, just transfer or dispose-Perform no treatment of system generated waste and transfer all such activities, as well as untreated excess facilities, to appropriate site-level functions.

2. Treatment, then transfer or dispose - Perform sufficient treatment on system generated waste to dispose within TWRS (e.g., the immobilized LLW) or transfer to site-level function for final disposition.

\section{ARCHITECTURAL SYNTHESIS}

Waste generated within this functional set will include fractions which cannot be handled by other site-wide functions. Therefore this set must perform some treatment of system generated waste and excess facilities prior to either disposal within TWRS (e.g., the immobilized LLW) or transfer as needed to site-level functions for final disposition as appropriate. 


\section{SYNTHESIS DEFINITION}

Process system waste to levels appropriate for receipt by other site functions; dispose generated HLW/TRU waste within this functional set.

4.4.2.3.1 Immobilize and Dispose Low-Level Waste (4.2.3.1). Receive pretreated LLW from the process waste (PW) function (via storage in Manage Tank Waste [MTW]), treat LLW, and dispose LLW onsite. This function includes; receipt of the waste from $\mathrm{PW}$, treatment of the waste by an immobilization process, disposal of the immobilized waste, and closure of the disposal site.

This function begins when the $L L W$ is received from PW. Treatment will continue until all waste shipped from $\mathrm{PW}$ is treated and the disposal site is closed.

\section{ALTERNATIVES CONSIDERED}

1. Waste Form:

a. Grout (i.e., mineral, salt) - The LLW is mixed with a slurry of cementitious materials to form a salt grout or a mineral grout.

b. Ceramic in grout - The $L L W$ is mixed with clays and calcined at $600{ }^{\circ} \mathrm{C}$ to $800{ }^{\circ} \mathrm{C}$ to form a ceramic powder. The powder is mixed with cementitious materials to form a grout.

c. Salt Polyethylene - The LLW slurry is dried to a solid powder that is mixed into molten polyethylene. It is then cast into containers.

d. Glass - The LLW solution is mixed with glass forming additives and fed to a glass melter. The LLW is converted to oxides and incorporated into the glass matrix.

2. Waste Disposal:

a. Onsite, permanent disposal

b. Onsite, retrievable for repackaging.

\section{ARCHITECTURAL SYNTHESIS}

The architectural selection for this function is containerized glass.

Public involvement and the TPA (TPA Change Control Number M-60-93-01, approved 1/25/94) have identified glass as the preferred $L L W$ form. However, the particular glass formulation must still be defined. Onsite retrievable disposal was selected to respond to stakeholder interest in retrievability for up to 50 years.

\section{SYNTHESIS DEFINITION}

Dispose of the LLW fraction of tank waste in containerized glass or glass cullet in a retrievable form. 
4.4.2.3.2 Disposition Gaseous Effluent (4.2.3.2). Filter, scrub, and exhaust treated gaseous effluent generated from facilities, tanks and processes. Exhaust effluent stream(s) to an external system.

This effort is ongoing and will terminate with the last process activity.

\section{ALTERNATIVES CONSIDERED}

1. Local treatment - Treat and release individual gaseous effluent streams at point of generation.

2. Central treatment - Collect combined gaseous effluent streams, treat and dispose at central facility.

3. Combination of local and central treatment - Treat and dispose most gaseous effluent streams at point of generation but collect those in close proximity of each other for treatment and disposal at a central facility.

\section{ARCHITECTURAL SYNTHESIS}

The architectural synthesis for this function is: Treat and dispose most gaseous effluent streams at point of generation but collect those in close proximity of each other for treatment and disposal at a central facility.

\section{SYNTHESIS DEFINITION}

Treat and dispose of gaseous effluents as appropriate.

4.4.2.3.3 Disposition of Liquid Effluent (4.2.3.3). Collect liquid effluent and store for processing or treat before discharging to the environment or to an external containment system.

This effort is ongoing and will terminate with the last process activity.

\section{ALTERNATIVES CONSIDERED}

1. Local treatment - Treat all liquid effluents at point of generation, to the point where a central discharge system can take over.

2. Central treatment - Treat al1 liquid effluents at a central treatment facility then discharge through another central system.

3. Combination of local and central treatment - Treat most of the liquid effluents point of generation and some at a central treatment facility, then route to a central discharge system.

\section{ARCHITECTURAL SYNTHESIS}

The architectural synthesis for this function is: Treat most of the liquid effluents at point of generation and some at a central treatment facility, then route to a central discharge system. 


\section{SYNTHESIS DEFINITION}

Treat liquid (aqueous) effluents to the point where discharge to function 4.5 process is acceptable.

4.4.2.3.4 Disposition Solid Waste (4.2.3.4). Prepare solid waste generated as a result of remediating tank waste for disposition. This includes segregating, characterizing, packaging, and transferring system generated solid waste. Sol id waste includes: High-level and low-level radioactive waste, LLMW and dangerous waste, TRU waste, mixed TRU and dangerous waste, dangerous waste, and nonradioactive nondangerous solid waste.

Disposition solid waste is ongoing and will continue as long as solid waste is generated by TWRS.

\section{ALTERNATIVES CONSIDERED}

1. Local treatment - Treat as necessary and package all solid waste at the point of generation before transfer to the site-level Remedy Solid Waste (4.3) function.

2. Central treatment - Treat as necessary and package all solid waste at a central TWRS treatment facility before transfer to the site-level Remedy Solid Waste (4.3) function.

3. Combination of local and central treatment - Treat as necessary and package some of the solid waste at the point of generation and the rest at a central TWRS treatment facility before transfer to the site-level Remedy Solid Waste (4.3) function.

\section{ARCHITECTURAL SYNTHESIS}

Use a combination of distributed and central treatment based on cost effectiveness and environmental performance.

\section{SYNTHESIS DEFINITION}

Treat solid wastes as necessary to be acceptable to function 4.3.

4.4.2.3.5 Disposition Excess Facilities (4.2.3.5). Evaluate (for possible reuse or deactivation), empty, decontaminate, and dispose of excess facilities accordingly. If reuse within TWRS is not an option, then the excess facility will be prepared for transfer to site-level Deactivate Facilities function (4.1) (D\&D) for closure, after the following activities: Identification and/or removal of chemical inventories, decontamination or stabilization of work areas, shut down nonessential support systems, disconnection of utilities, and isolation of tanks (where applicable). Excess facilities are those structures used in the storage, treatment, or processing of tank waste which have no currently identifiable programmatic uses. Excess facilities include: DSTs, SSTs, miscellaneous tanks, transfer lines, pretreatment structures, LLW/HLW facilities and any other facilities that support the TWRS process. 
Processing through the Disposition Excess Facilities is ongoing, specifically clean-up activities on existing, inactive excess facilities (e.g., 244-AR Vault, 244-CR Vault, 242S Evaporator) awaiting transfer to the site Tevel Deactivate Facilities (4.1) function. This process ends when the facility meets the acceptance criteria for site-level reuse or transfer for. closure.

\section{ALTERNATIVES CONSIDERED}

Following cessation of operations, each excess facility will be transferred to the Site Deactivate Facilities (4.1) function for deactivation and $D \& D$.

\section{ARCHITECTURAL SYNTHESIS}

Following cessation of operation, each excess facility will be deactivated prior to transfer to the Site Deactivate Facilities (4.1) function for $D \& D$.

\section{SYNTHESIS DEFINITION}

Transfer excess tank waste facilities to function 4.1.

4.4.2.3.6 Disposition Reusable Materials (4.2.3.6). Evaluate for reuse (before acceptance), collect, store, treat (e.g., recycled water with corrosion inhibitors), package, and transfer materials for TWRS and site-level reuse. Major types of reusable materials include water, nitrous oxide, concrete (for road aggregate), and scrap metal (e.g.s iron, steel, railroad rails, salvage drums/gas cylinders, aluminum, and copper from electrical wiring). activity.

This process is ongoing and will terminate with the last process

\section{ALTERNATIVES CONSIDERED}

1. Provide localized recycling/reuse.

2. Provide centralized recycling/reuse.

3. Combination of localized and centralized recycling/reuse.

\section{ARCHITECTURAL SYNTHESIS}

Combination of localized and centralized recycling/reuse based on economic feasibility.

SYNTHESIS DEFINITION

Combination of localized and centralized recycling/reuse. 


\subsubsection{Remedy Solid Waste (4.3)}

The REMEDY SOLID WASTE (4.3) function is charged with disposition of buried wastes and solid waste materials generated during past missions as well as solid.wastes generated during the cleanup mission, and solidification of hazardous liquids.

\section{ALTERNATIVES CONSIDERED}

Buried/Retrievably Stored Wastes:

1. Leave in place without disturbing the trench contents. Place a RCRA cover over the trenches to prevent any dispersal of contamination into the groundwater.

2a. Evaluate all historical records to determine where wastes that might be classified as TRU wastes might be buried. Retrieve those sections of the trenches containing post-1970 retrievably stored suspect TRU waste only and process the retrieved wastes. Fill the disturbed trench. Leave in place without disturbing the remainder of the trench contents. PIace a RCRA cover over the trenches to prevent any dispersal of contamination into the groundwater.

2b. Evaluate all historical records to determine where wastes that might be classified as TRU wastes might be buried. Retrieve those sections of the trenches containing post-1970 retrievably stored waste confirmed as being TRU waste only (leave suspect waste which historical records show is LLW) and process the retrieved wastes. Fill the disturbed trench. Leave in place without disturbing the remainder of the trench contents. Place a RCRA cover over the trenches to prevent any dispersal of contamination into the groundwater.

3. Evaluate all historical records to determine where wastes that might be classified as TRU wastes might be buried. Retrieve those sections of the trenches containing suspect TRU or suspect mixed waste only and process the retrieved wastes. Fill the disturbed trenches. Leave in place without disturbing the remainder of the trench contents. Place a RCRA cover over the trenches to prevent any dispersal of contamination into the groundwater.

4. Assume that the historical records will not provide adequate guidance regarding physical, radionuclide, and hazardous characteristics, and retrieve all wastes currently in the burial grounds. Treated wastes will be sent to disposal in accordance with contamination control requirements. All onsite disposal would be in trenches designed and constructed to the latest criteria and provided with the appropriate closure cap. 
5. Evaluate all historical records to determine where wastes that might be classified as TRU wastes and LLMW might be buried. Retrieve those sections of the trenches containing suspect TRU or suspect MW and process the retrieved wastes. Fill the disturbed trench. Leave in place without disturbing the remainder of the trench contents. Place a RCRA cover over the trenches to prevent any dispersal of contamination into the groundwater.

6. Assume that the historical records will not provide adequate guidance and retrieve all pre-1970 wastes, process them as suspect TRU and return the trenches to contamination free areas. In addition assume historical records will not provide adequate guidance regarding hazardous characteristics and retrieve all post-1970 wastes, process them as suspect MW and return the trenches to contamination free areas. Treated wastes will be sent to disposal in accordance with the contamination control requirements. All onsite disposal would be in trenches designed and constructed to latest criteria and provided with the appropriate RCRA cap.

\section{Storage:}

1. Store, in a regulatory compliant manner, waste pending availability of treatment capability. Store wastes that have no currently defined treatment criteria until such treatment capability exists, either onsite or offsite. Store treated wastes until acceptable disposal facilities become available.

2. Defer acceptance of selected wastes until treatment capability exists. Store treated wastes until acceptable disposal facilities become available.

\section{Treatment:}

1. Process the radioactive wastes (transuranic mixed waste [TRUM]/TRU and $L L M W / L L W)$ to meet the minimum requirements of the disposal waste acceptance criteria (WAC). For LLMW, meet the Land Disposal Restrictions criteria using the Best Demonstrated Available Technology treatments. Broker hazardous waste to an offsite commercial operation.

2. As in 1. above, but also minimize the waste volume concurrent with treatment.

3. Process as in 1. above but only for a portion of the radioactive wastes and assume that treatment for a selected portion of the waste to meet the minimum requirements of the disposal waste would be processed in an offsite commercial or DOE facility.

4. Require waste generators to treat the waste to the disposal facility acceptance criteria prior and provide no treatment capability.

5. In-situ treat buried wastes to acceptable land disposal standards and leave in place for disposal. 
Disposal:

1. Provide onsite disposal for all LLW, LLMW, TRU, and hazardous wastes. Develop onsite TRU disposal criteria; use current disposal criteria for LLW, LLMW and hazardous wastes.

2. Provide onsite disposal for all LLW, LLMW, TRU. Develop onsite TRU disposal criteria. Hazardous waste will be disposed offsite.

3. Provide onsite disposal for all LLW and LLMW. Each disposal facility will meet applicable requirements and performance assessment. TRU waste and hazardous waste will be disposed offsite.

4. Provide onsite disposal for all LLW only. Each disposal facility will meet applicable requirements and performance assessment. 'LLMW, TRU waste and hazardous waste will be disposed offsite.

5. Provide no onsite disposal for any waste. LLW, LLMW, TRU, and hazardous waste will be disposed offsite.

6. Combine solid waste disposal trenches with environmental restoration\decontamination and decommissioning disposal needs. Prepare appropriate disposal WAC and modify treatment plans as required.

\section{ARCHITECTURAL SYNTHESIS}

The current architecture is based on a number of decisions and requirements depending on the waste types: transuranic, mixed hazardous and low-level waste, low-level waste, and hazardous waste.

A decision has been made in the Hanford Defense Waste Environmenta] Impact Statement Record of Decision (Federal Register, Volume 53, p. 12449) to retrieve all retrievably stored transuranic waste and process it along with any newly generated transuranic waste to meet waste. acceptance criteria for disposal at the Waste Isolation Pilot Plant.

The mixed hazardous and low-level waste is stored, treated, and/or disposed according to the requirements of all applicable Department of Energy orders and shall also be regulated by the appropriate regional authorities (Washington State Department of Ecology per Washington Administrative Code 173-303, Dangerous Waste Regulations) under the Resource Conservation and Recovery Act.

The $L L W$ is stored, treated, and/or disposed according to the requirements of all applicable Department of Energy orders. LLW that has radionuclide concentrations greater than category 3 concentration limits (as defined in the Hanford Site Solid Waste Acceptance Criteria, WHC-EP-0063-4) shall be stored until a final policy decision is made regarding ultimate disposition of this material. 
The hazardous waste is stored, treated, and/or disposed according to the requirements by the appropriate regional authority (Washington State Department of Ecology per Washington Administrative Code 173-303, Dangerous Waste Regulations) under the Resource Conservation and Recovery Act.

\section{SYNTHESIS DEFINITION}

For buried/retrievably stored waste, all historical records will be evaluated to determine where wastes that might be classified as TRU are buried. Retrieve the sections of trenches containing post-1970 retrievably stored suspect TRU waste and process the retrieved wastes. Fill the disturbed trenches. Leave in place without disturbing the remainder of the trench contents. Place a RCRA cover over the trenches to prevent any dispersal of potential contamination into the groundwater.

Regarding storage, wastes requiring treatment are stored, in a regulatory compliant manner, pending availability of treatment capability. Wastes that have no currently defined treatment criteria are stored until such treatment capability exists, either onsite or offsite. Treated wastes are stored until acceptable disposal facilities become available.

Waste treatment will process the radioactive wastes (TRUM/TRU and LLMW/LLW) to meet the requirements of the disposal WAC. For TRU waste, the treated waste will meet the WIPP WAC. For LLMW, the treated waste will meet concentration based standards or specific treatment based on Land Disposal Restrictions.

Hazardous waste will be contracted to an offsite commercial operation. Onsite disposal is provided for al1 LLW and LLMW. TRU waste and hazardous waste will be disposed offsite.

\subsubsection{Maintain Solid Waste Safety And Compliance Envelope (4.3.1).} Continually assess and maintain the waste form and the facility structures and operations in a safe and compliant condition. Includes maintaining a qualified facility staff, and maintaining required safety/compliance documentation.

\section{ALTERNATIVES CONSIDERED}

1. Meet the minimum safety and compliance requirements without regard to continuous improvement.

2. Use improvement techniques (Value Engineering, Total Quality Management TQM, probabilistic risk analysis, etc.) and other improvement techniques to continually refine the quality of safety and compliance.

\section{ARCHITECTURAL SYNTHESIS}

A workable approach to maintaining the safety and security envelope is in place. Continuous improvement of this embedded process should be pursued to minimize personnel safety exposure and environmental risk. 


\section{SYNTHESIS DEFINITION}

Utilize Value Engineering and Total Quality Management TQM techniques for continuous improvement in the Solid Waste safety and compliance envelope.

\subsection{Maintain Safe And Compliant Solid Waste Operational}

Environment (4.3.1.1). Continually assess and maintain the solid waste operational environment in a safe and compliant condition, with respect to applicable environmental requirements, DOE Orders, and all other applicable codes, standards, and company procedures.

\section{ALTERNATIVES CONSIDERED}

1. Comply with all requirements, except where waivers to requirements are more cost effective without degrading the safety and compliance envelope.

2. Comply with all requirements without utilizing any waivers.

\section{ARCHITECTURAL SYNTHESIS}

If found to be cost effective, waivers to regulations will be pursued if and only if there is no degradation in the safety and compliance envelope.

\section{SYNTHESIS DEFINITION}

Comply with all requirements, except where waivers to requirements are more cost effective without degrading the safety and compliance envelope.

\subsection{Maintain Safe And Compliant Solid Waste Systems, Equipment And} Structures (4.3.1.2). Continually assess and maintain the solid waste facility systems, equipment, and structures, and their operations in a safe condition. Maintain a qualified solid waste staff, and maintain required solid waste facility and operating documentation.

\section{ALTERNATIVES CONSIDERED}

1. DOE-owned, contractor-operated facilities acquired through capital projects.

2. Privatization of facilities to meet DOE needs.

\section{ARCHITECTURAL SYNTHESIS}

Provide the facilities to meet the needs of DOE and also provide for the long-term economic stability of the region.

\section{SYNTHESIS DEFINITION}

Pursue DOE-owned, contractor-operated facilities acquired through capital projects. Use privatized facilities where appropriate and found to provide greater benefit than a DOE-owned facility. 
4.4.3.1.3 Maintain Safe And Compliant Solid Waste Documentation (Safety Analysis Reports, Operational Safety Requirements, etc.) (4.3.1.3). Maintain required solid waste facility and operating documentation related to safe and compliant operations.

\section{ALTERNATIVES CONSIDERED}

1. Use existing methods without change.

2. Use V.E. and TQM to improve the process.

\section{ARCHITECTURAL SYNTHESIS}

Continual improvements of existing processes.

\section{SYNTHESIS DEFINITION}

Use V.E. and TQM to improve the process.

4.4.3.1.4 Maintain Qualified Solid Waste Staff (4.3.1.4). Provide solid waste facility-specific training, testing, and training records maintenance to ensure solid waste facility staff remain trained, qualified, and certified throughout the solid waste facility operation.

\section{ALTERNATIVES CONSIDERED}

None

ARCHITECTURAL SYNTHESIS

None

\section{SYNTHESIS DEFINITION}

None

4.4.3.1.5 Assess Solid Waste Safety And Compliance State (4.3.1.5). Perform/respond to oversight assessments and perform appropriate self assessments of the solid waste facility activities to evaluate the facility and operations safety and compliance status.

\section{ALTERNATIVES CONSIDERED}

1. Use existing approach without change.

2. Use V.E. and TQM to improve the process.

ARCHITECTURAL SYNTHESIS

Continual improvements of existing processes 
WHC-EP-0779

\section{SYNTHESIS DEFINITION}

Use V.E. and TQM to improve the process.

4.4.3.2 Receive Solid Waste (4.3.2). Retrieve legacy solid waste and receive solid waste generated during cleanup operations and solid waste from other missions.

\section{ALTERNATIVES CONSIDERED}

1. Prepare standardized WAC for use by all waste generators. Address unusual situations on a case-by-case basis.

2. Address all waste shipments on a case-by-case basis.

\section{ARCHITECTURAL SYNTHESIS}

A high-performing architecture will provide the optimum mix of fixed criteria plus allowing for the unusual cases that will arise. This approach allows all waste generators to work to a common standard, standardizes the activities related to waste acceptance by Solid Waste Operations, minimizes extra costs and technical and safety related uncertainties related to off-normal operations.

\section{SYNTHESIS DEFINITION}

Develop standardized WAC (for treatment, storage, disposal as necessary) for all currently identified waste and likely future shipments of waste to the Hanford Site. Address unusual situations on a case-by-case basis Broaden the criteria, as required, to address any unexpected waste receipts.

\subsection{Retrieve Existing Solid Waste (4.3.2.1). Retrieve legacy} solid waste; includes retrieval planning and solid waste access and removal, obtains waste characterization samples, generates waste information, establishes retrieval capability requirements, and forecasts future retrieval operations.

\section{ALTERNATIVES CONSIDERED}

1. Retrieve waste from trenches and buildings in a manner that provides adequate safeguards and security and which meets the timetable for treatment and disposal by existing and future treatment facilities. Emphasis is on minimizing any future degradation of the waste package container and minimizing any future release of contaminants to the environment.

2. As in 1. above, but the emphasis is on delaying the retrieval operations to better match the availability of treatment capability (thereby reducing interim storage needs)。 


\section{ARCHITECTURAL SYNTHESIS}

It is assumed that a prompt retrieval of target waste, and the resulting costs of storage, is preferable to allowing the potential for any additional release of contamination to the trench (and the resulting worker hazards and extra costs of eventual recovery of the contaminated trench).

\section{SYNTHESIS DEFINITION}

Retrieve waste from trenches and buildings which meets the timetable for treatment and disposal by existing and future treatment facilities. Emphasis is on minimizing any future degradation of the waste package container and minimizing any future release of contaminants to the environment.

4.4.3.2.2 Receive New Solid Waste (4.3.2.2). Receives solid waste generated during Hanford Cleanup mission operations and from other missions; includes solid waste receipt planning, characterization information verification for acceptance, establishes receipt capability requirements, and forecasts future receipt operations.

\section{ALTERNATIVES CONSIDERED}

1. Continue to use Hanford as a National solid waste disposal site capable of receiving wastes from a spectrum of governmental generators. Add nongovernmental entities to the scope of generators sending waste to the Hanford Site for management.

2. Continue to accept wastes from all currently identified onsite and offsite governmental generators in accordance with latest guidelines.

3. Accept only wastes from all onsite generators and no longer accept any waste from offsite generators.

\section{ARCHITECTURAL SYNTHESIS}

The Hanford solid waste disposal system is a unique system in which long term isolation of solid wastes can be assured. Because of this uniqueness, new solid waste receipts from offsite can be expected as pressing needs develop throughout the country. Disposition at Hanford must be managed through a national policy on solid waste disposal which reflects the capability of the 200 Area for solid waste disposal.

\section{SYNTHESIS DEFINITION}

Continue to accept wastes from all onsite and offsite generators in accordance with national policy guidelines. Pursue the option of providing national radioactive materials disposal services to both government and nongovernment entities. 
4.4.3.3 Characterize Solid Waste (4.3.3). Identify, inventory, and characterize the waste by reviewing the process operations (current and historical), by reviewing new waste information and by sampling and analyzing the waste inventory. Assess the current condition of the waste. Archive the results of these investigations.

\section{ALTERNATIVES CONSIDERED}

1. Maximize use of nonintrusive investigations for characterization for storage and treatment.

2. Rely heavily on intrusive methods for characterization.

\section{ARCHITECTURAL SYNTHESIS}

Cost efficiency and as low as reasonably achievable (ALARA) concerns strongly favor nonintrusive characterization to a detail which meets regulations and provides sufficient data for TSD operations. Nonintrusive methods will minimize use of off-line analyses but close coupled analytical processes should be used whenever nonintrusive methods are not available. Modern but well proven data management methods should be used.

\section{SYNTHESIS DEFINITION}

For Stored and Newly Generated Waste:

The solid waste must be characterized, to varying degrees depending on the operations in question, for both storage, treatment and for disposal. The waste generators must adequately characterize the incoming wastes to permit storage under Hanford Site permits and for planning of treatment, as well as to prepare the necessary shipping manifest. Treatment facilities may need to augment the incoming characterization date to refine treatment plans, and they will be required to characterize the waste to the degree required for preparing shipping manifests and to demonstrate treatment to disposal WAC standards. Modern but well proven data management methods should be used for the characterization system.

For Retrievably Stored Waste:

Maximize use of nonintrusive characterization which meets regulations and provides just sufficient data for TSD. Close coupled analytical processes should be used whenever nonintrusive methods are not available. Modern but well proven data management methods should be used for the characterization system. Characterization at retrieval will be adequate for storage prior to treatment: to some degree, characterization for treatment will have to occur as part of the actual processing operation.

4.4.3.3.1 Acquire Solid Waste Process Knowledge (4.3.3.1). Review the solid waste processing records, process documentation, and submitted documentation to acquire knowledge about the solid waste generation process. Conduct interviews with solid waste generators as needed to obtain such knowledge and perform a safety review of the solid waste. Provide this process knowledge to enable the solid waste characterization assessment. 


\section{ALTERNATIVES CONSIDERED}

None considered.

ARCHITECTURAL SYNTHESIS

None considered.

\section{SYNTHESIS DEFINITION}

N/A.

4.4.3.3.2 Analyze Sol id Waste Inventory (4.3.3.2). Receive the solid waste samples and perform analysis thereof to obtain required characterization data. Provide this analysis information to enable the solid waste characterization assessment. Transfer the solid waste samples and accompanying characterization data to solid waste archives. Send any excess solid waste samples on to the Receive Solid Waste function to facilitate disposition.

\section{ALTERNATIVES CONSIDERED}

None considered.

\section{ARCHITECTURAL SYNTHESIS}

None considered.

\section{SYNTHESIS DEFINITION}

N/A

4.4.3.3.3 Archive Solid Waste Samples/Characterization Data (4.3.3.3). Provide archival storage and retrieval operations for the analyzed solid waste samples and the accompanying characterization data.

\section{ALTERNATIVES CONSIDERED}

None considered.

\section{ARCHITECTURAL SYNTHESIS}

None considered.

\section{SYNTHESIS DEFINITION}

N/A

4.4.3.3.4 Assess Solid Waste Characterization Information (4.3.3.4). Evaluate the solid waste characterization information, consisting of generator request information, process knowledge information, and waste sample characterization data, against the solid waste disposition requirements and 
provide validation of meeting the disposition requirements. Determine any additional solid waste process knowledge needs to support disposition.

\section{ALTERNATIVES CONSIDERED}

No alternatives considered.

ARCHITECTURAL SYNTHESIS

None, no alternatives considered.

\section{SYNTHESIS DEFINITION}

Provide capability to assess adequacy of characterization information.

4.4.3.4 Determine Solid Waste Disposition Requirements (4.3.4). Compile and sort imposed requirements, define requirements that result from proposed solutions and required capabilities, and assess constraints under which the function must operate.

\section{ALTERNATIVES CONSIDERED}

No alternatives considered, architecture is self-evident. While there are alternatives related to achieving the necessary capability (e.g., when a particular facility treatment will be on line, the annual treatment rate) and there are alternatives related to the specific facilities required, there is no alternative to develop the disposition requirements for the waste to be managed.

\section{ARCHITECTURAL SYNTHESIS}

None, no alternatives considered.

\section{SYNTHESIS DEFINITION}

To be determined

4.4.3.4.1 Compile Imposed Solid Waste Requirements (4.3.4.1). Collect state, federal, DOE, and any other regulatory documents which pertain to transport, handling, packaging and disposition of solid waste.

\section{ALTERNATIVES CONSIDERED}

(To be addressed in 1.0).

\section{ARCHITECTURAL SYNTHESIS}

(To be addressed in 1.0). 


\section{SYNTHESIS DEFINITION}

(To be addressed in 1.0).

4.4.3.4.2 Evaluate Solid Waste Requirements For Disposition (4.3.4.2). Review and evaluate list of solid waste disposition requirements to verify applicability and completeness for disposition categories.

\section{ALTERNATIVES CONSIDERED}

(To be considered).

\section{ARCHITECTURAL SYNTHESIS}

(To be considered).

\section{SYNTHESIS DEFINITION}

(To be considered).

4.4.3.4.3 Prepare Solid Waste Disposition Specifications (4.3.4.3). Generate specifications for solid waste operations including treatment, packaging, certification, storage, shipping, disposition, and archiving samples and records.

\section{ALTERNATIVES CONSIDERED}

None considered.

ARCHITECTURAL SYNTHESIS

None considered.

\section{SYNTHESIS DEFINITION}

$N / A$.

4.4.3.5 Disposition Solid Waste (4.3.5). Package and certify the solid waste, store or ship it as needed, treat and/or immobilize it, and accomplish. final disposition.

\section{ALTERNATIVES CONSIDERED}

1. Maximize use of existing facilities (on or offsite) to the extent that activities can be conducted safely and cost-effectively. Build any new facilities at Hanford as required to complete the disposition system.

2. Build all new facilities at the Hanford Site to meet the latest codes and standards to provide the most up to date facilities possible for the disposition system. 
3. Build the minimum number of facilities possible and rely on offsite disposition capabilities. Provide only enough storage capacity to hold waste awaiting offsite transport for disposition.

\section{ARCHITECTURAL SYNTHESIS}

A high-performing synthesis should rely on use of existing facilities where these are safe and cost-effective and construction of new disposal facilities as needed to complete disposition. Use of "all new" facilities and exclusion of offsite disposal possibilities are likely to elevate disposal costs.

\section{SYNTHESIS DEFINITION}

Use existing facilities where activities can be conducted safely and cost-effectively. Build new facilities at Hanford as necessary to meet the disposition requirements.

4.4.3.5.1 Treat Solid Waste (4.3.5.1). Provide treatment of solid waste to neutralize, immobilize, and stabilize it for storage and final disposition.

\section{ALTERNATIVES CONSIDERED}

1. Treat solid wastes to meet minimum disposal acceptance criteria established by regulatory bodies and site specific performance requirements.

2. Treat solid wastes to exceed disposal acceptance criteria established by regulatory bodies and site specific performance requirements. Consideration would be given to:

- Minimizing treated volume (thereby minimizing disposal size requirements)

- Maximizing the destruction of hazardous MW versus otherwise acceptable treatments that solidify or stabilize the waste, providing a final waste form that minimized the potential for contamination release in the expected environment

- Life cycle costs, including consideration of long term disposal area monitoring costs

- ALARA considerations related to worker exposure

- Improvements in site specific performance.

3. Develop completely new solid waste treatment procedures appropriate to the Hanford situation and obtain regulatory approval. 


\section{ARCHITECTURAL SYNTHESIS}

The current basel ine approach to treatment of Solid Wastes assumes that a life-cycle cost analysis would show that treatment to the minimum standards will result in minimum life-cycle costs. Public perception of the adequacy of existing treatment standards may result in a revision to this plan. Reduction in volume is expected to be a public preference such that volume minimization will be added to the minimum standard approach.

\section{SYNTHESIS DEFINITION}

Treat solid waste as needed to meet minimum standards for disposal site WAC. Develop adequate treatment approaches and submit for regulatory approval. Minimize volume when appropriate.

4.4.3.5.2 Package Solid Waste (4.3.5.2). Containerize the treated solid waste in a container suitable for the waste type. Provide solid waste packaging documentation including packaging certifications and solid waste feedstock traceability. Provide appropriate labeling and inspection of the containers of solid waste.

\section{ALTERNATIVES CONSIDERED}

1. Package solid wastes to meet the minimum packaging requirement established by regulatory bodies.

2. Package solid waste to exceed solid waste packaging requirements.

3. Develop new solid waste packaging methods appropriate to the Hanford situation and obtain regulatory approval.

\section{ARCHITECTURAL SYNTHESIS}

Cost effectiveness suggests that packaging should only meet minimum requirements.

\section{SYNTHESIS DEFINITION}

Package solid waste as needed to meet minimum standards for transportation, interim storage, and final disposal. Use standard waste packages to the maximum extent possible.

4.4.3.5.3 Certify Solid Waste (4.3.5.3). Certify that the solid waste was treated according to the disposition requirements and that the documentation is in order to allow release of the solid waste package for storage and disposition. This function will also send samples back to the characterization function if needed. 


\section{ALTERNATIVES CONSIDERED}

1. Certify solid wastes to meet minimum certification criteria established by regulatory bodies. Review all criteria to evaluate any potential for savings via simplification or deletion of requirements or statistical methods to minimize sampling.

2. Certify solid waste to exceed solid waste certification requirements.

3. Develop new solid waste certification methods appropriate to the Hanford situation and obtain regulatory approval.

\section{ARCHITECTURAL SYNTHESIS}

Cost effectiveness suggests that certification should only meet existing regulations rather than exceed them.

Certification testing is very expensive. Consideration should be given to requesting selected changes in the regulations to more properly address the LLW, LLMW, and TRUM characterization and certification needs. In general, the current protocols are directed toward industries that are significantly different from that of the Hanford Site remediation effort. Protocols dealing with the characterization and certification process should be individually reviewed and assessed as to applicability. Where changes appear warranted, a dialogue with the regulators should be opened to determine the steps necessary to make the protocols more appropriate, and hopefully, less costly and less time consuming.

\section{SYNTHESIS DEFINITION}

Certify solid waste as needed to meet minimum standards. Seek selected changes in the regulations to more properly address the LLW, LLMW, and TRUM characterization and certification needs.

\subsection{Store Solid Waste (4.3.5.4). Store the solid waste before} shipment to the disposal site.

\section{ALTERNATIVES CONSIDERED}

1. Store solid wastes to meet minimum storage requirements by the regulatory bodies.

2. Store solid waste to exceed solid waste storage regulations.

3. Develop new solid waste storage methods appropriate to the Hanford situation and obtain regulatory approval. Evaluate the intent of the regulations and propose modified standards which provide adequate protection to the worker, public and environment that apply to Hanford specific storage conditions. 


\section{ARCHITECTURAL SYNTHESIS}

Cost effectiveness suggests that storage should only meet existing regulations rather than exceed them. However, some storage requirements may not fit the specific situation for some Hanford wastes but must be met regardless of their initial intent. For situations where significant cost savings are possible, concurrent with retaining an adequate safety and security envelope, develop proposals to the appropriate regulatory bodies to make regulations more appropriate to the Hanford situation.

\section{SYNTHESIS DEFINITION}

Store solid waste as needed to meet minimum standards. Develop and advance improved storage regulations.

4.4.3.5.5 Ship Solid Waste (4.3.5.5). Receive the certified solid waste package and prepare the necessary shipment requests and documentation. Coordinate the solid waste package shipment with shippers and receivers to verify that the final waste disposition was accomplished. Document the final solid waste disposition status.

\section{ALTERNATIVES CONSIDERED}

1. Ship solid wastes meeting minimum shipment requirements defined by the regulatory bodies.

2. Ship solid waste exceeding solid waste shipping requirements.

3. Develop new solid waste shipping methods appropriate to the Hanford situation and obtain regulatory approval.

\section{ARCHITECTURAL SYNTHESIS}

Cost effectiveness suggests that shipment should only meet existing regulations rather than exceed them. Requirements will continually be reviewed to evaluate any potential for savings.

\section{SYNTHESIS DEFINITION}

Ship solid waste as needed meeting minimum standards.

\subsection{Dispose Solid Waste (4.3.5.6). Schedule the sol id waste} package disposal and prepare the waste transport package and disposal documentation. Provide final inspection of the solid waste package load and place in disposal site. Close the disposal site in regulatory compliance and provide institutional controls and closure security to maintain the disposal site security and integrity.

\section{ALTERNATIVES CONSIDERED}

1. Dispose of solid wastes meeting minimum disposal requirements defined by the regulatory bodies.

2. Dispose of solid waste exceeding solid waste disposal requirements. 
3. Develop new solid waste disposal methods appropriate to the Hanford situation and obtain regulatory approval.

\section{ARCHITECTURAL SYNTHESIS}

Cost effectiveness suggests that disposal should only meet minimum existing requirements rather than exceed them.

An extensive analytical study, the Hanford Site Specific Performance Assessment (ref. 2), has been conducted to evaluate the potential for contamination release from the 200 Area burial grounds. Based on this data, which has had extensive peer review by appropriate staff, the potential for contamination release is well within acceptable probability limits with the proviso that specific LLW and LLMW wastes are properly packaged and located within the trench. It is well to note that the critical release parameter is not a release to the groundwater, but due

- to intrusion by future generations via excavating the site. Packaging improvements are not likely to improve any chance that some future generation might want to excavate the site. This is better addressed via an appropriate trench cap and suitable site markers, than, for example, heavier gage steel in boxes or drums.

\section{SYNTHESIS DEFINITION}

Dispose of solid waste meeting minimum regulatory standards.

4.4.3.5.7 Archive Solid Waste Process Samples and Records (4.3.5.8). Provide archival storage and retrieval operations for the analyzed solid waste process samples and the accompanying analysis data.

\section{ALTERNATIVES CONSIDERED}

1. Record solid waste disposition meeting minimum documentation requirements defined by the regulatory bodies.

2. Record solid waste disposition exceeding solid waste disposition documentation regulations.

3. Develop new solid waste disposal documentation methods appropriate to the Hanford situation and obtain regulatory approval.

\section{ARCHITECTURAL SYNTHESIS}

Cost effectiveness suggests that documentation should only meet existing regulations rather than exceed them.

\section{SYNTHESIS DEFINITION}

Record solid waste disposition meeting minimum standards. 


\subsubsection{Remedy/Restore Sites, Facilities, and Groundwater (4.4)}

The REMEDY/RESTORE SITES, FACILITIES, AND GROUND WATER (4.4) function restores sites, deactivated facilities, ground water, and related items to an acceptable state. This function includes restoration of chemically contaminated lands, and removal or disposition of buildings, fission reactors, chemical processing plants, infrastructure, etc. This function includes new as well as legacy items.

\section{ALTERNATIVES CONSIDERED}

This function relies on standard construction and D\&D techniques for restoration of sites, facilities, and groundwater for all remedial actions taken outside the 200 areas. The key choices for these functions include only the transportation methods. All other functions were implemented in the same way. The five alternatives considered are as follows:

1. Semi-truck and container haulage and container rail transport with one disposal trench. (ERDF, Environmental Restoration Disposal Facility)

2. Semi-truck and container haulage and transport with one disposal trench. (ERDF)

3. Semi-truck and container trailer haulage and trailer rail transport with one disposal trench. (ERDF)

4. Alternative A with individual disposal trenches for each waste type (e.g., mixed, low level, high activity, and hazardous).

5. A7ternative A with 2 disposal trenches.

\section{ARCHITECTURAL SYNTHESIS}

Based on criteria for worker safety, volume throughput, cost, technological integration, and regulatory complexity, and considering uncertainty in the data; Alternatives 1, 4, and 5 were the preferred al ternatives. TPA milestone M-70 provides directed architecture for ERDF of single 200 area disposal trench.

\section{SYNTHESIS DEFINITION}

Restore sites, deactivated facilities, ground water, and related items to an acceptable state. Activities include restoration of chemically contaminated 1ands, and removal or disposition of buildings, fission reactors, chemical processing plants, infrastructure, and utilities, and removal by $1,4,5$ to the 200 area disposal site (ERDF).

4.4.4.1 Implement ER Capabilities and Support (4.4.1). Support functions will be provided at each site (i.e., 100 Area and disposal facility) and all resources, plans, and procedures will be provided. 
WHC-EP-0779

\section{ALTERNATIVES CONSIDERED}

This function has not been analyzed for alternatives.

ARCHITECTURAL SYNTHESIS

N/A.

\section{SYNTHESIS DEFINITION}

Support functions will be provided at each site (i.e., 100 Area and disposal facility) and all resources, plans, and procedures will be provided.

4.4.4.2 Perform Remedial Action $(4,4.2)$. The Remedial Action (RA) area is cleaned up to acceptable levels for intended land use.

\section{ALTERNATIVES CONSIDERED}

All alternatives utilized the same standard methods of excavation, containerization, characterization, tracking, remobilization prevention, and 1 and reclamation. Three approaches were evaluated only for transportation:

1. Truck-trailer haulage to the rail transfer station, and rail flatcar container transport to the ER Disposal Facility.

2. Truck-trailer haulage and transport to the ER Disposal Facility.

3. Truck-trailer haulage to the rail transfer station, and rail flatcar trailer transport to the ER Disposal Facility.

\section{ARCHITECTURAL SYNTHESIS}

Based on criteria for worker safety, volume throughput, cost, technological integration, and regulatory complexity, and considering uncertainty in the data; Alternative 1 was selected resulting from highest ranking using an objective decision process.

\section{SYNTHESIS DEFINITION}

Clean up RA area to acceptable level use criteria by gross removal of contaminants, rubble and machinery. Use truck-trailer haulage and rail transfer to the 200 area ER disposal site.

\subsubsection{Decontaminate and Decommission Surplus Facilities (4.4.3).} Contaminated facilities are decontaminated and demolished along with the deactivated surplus facilities, and sites are reclaimed for intended land use.

\section{ALTERNATIVES CONSIDERED}

All alternatives utilized the same standard methods of excavation, containerization, characterization, tracking, remobilization prevention, 
and 1 and reclamation. Three approaches were evaluated only for transportation:

1. Truck-trailer haulage to the rail transfer station, and rail flatcar container transport to the ER Disposal Facility.

2. Truck-trailer haulage and transport to the ER Disposal Facility.

3. Truck-trailer haulage to the rail transfer station, and rail flatcar trailer transport to the ER Disposal Facility.

\section{ARCHITECTURAL SYNTHESIS}

Based on criteria for worker safety, volume throughput, cost, technological integration, and regulatory complexity, and considering uncertainty in the data; Alternative 1 was selected resulting from highest ranking using an objective decision process.

\section{SYNTHESIS DEFINITION}

Contaminated facilities are decontaminated and demolished along with the deactivated surplus facilities, and sites are reclaimed for intended land use. Contaminated materials and rubble are transported to the ER disposal site by truck-trailer haulage and rail.

\subsubsection{Manage Aqueous Wastes (4.5)}

Manages and treats aqueous wastes which are generated by the other functions under (4.0) and ongoing operations (Pacific Northwest Laboratory [PNL], sanitary wastes). Develops an Aqueous Waste Disposition Plan, transports and receives aqueous waste, treats the aqueous waste (if required), and dispositions the waste. Aqueous wastes which would result in the treatment facility operating outside of the safety and regulatory envelope will not be accepted. TRU wastes will not be processed and the concentration of TRU's in aqueous waste processed must be below established limits.

Appropriate and required documentation must accompany all aqueous waste.

\section{ALTERNATIVES CONSIDERED}

1. Dispose of permitted aqueous wastes by surface percolation.

2. Dispose of Aqueous wastes by permitted evaporation.

3. Maximize aqueous recycle to avoid TSD (process operations, laboratories, and directly related infrastructure) liability.

4. Obtain permits for river disposal where appropriate, terminate river disposal for noncompliant streams.

5. Use installed TSD infrastructure for all mission activities; handle projected surges or demand growth by recycle instead of adding facilities or expanding the base capacity. 
6. Use installed TSD infrastructure for all mission activities; handle surges and demand growth by adding surge capacity.

7. Transfer to local offsite nongovernmental TSD facilities and/or turnover existing or new TSD infrastructure to private operators/owners.

\section{ARCHITECTURAL SYNTHESIS}

Soil column disposal for treated effluents with residual tritium affords decay time before river contact. Extensive recycle would el iminate the need for expansion of current facilities. Discharges originating outside the 200 Area may compositionally and logistically suitable for river disposal.

The synthesis alternative for this function consists of (1) maximum use of recycling to minimize disposal volumes and to reduce TSD costs, (2) use of currently infrastructure for land disposal, use of river disposal where permittable, and use of nongovernmental TSD capability where possible.

\section{SYNTHESIS DEFINITION}

Dispose of all mission related aqueous wastes by providing required process operations, laboratories, and directly related utility infrastructure. Use Aqueous recycling to minimize disposal volumes and to reduce TSD costs, current infrastructure for 1 and disposal, river disposal where permittable, nongovernmental TSD capability where possible.

4.4.5.1 Maintain Aqueous Waste Safety and Compliance Envelope (4.5.1). Maintains the facility structure, qualified staff, safe and compliant equipment, documentation and provides assessment of safety and compliance states. Provides all necessary resources for safe and compliant operation in accordance with governing safety codes and regulations.

\section{ALTERNATIVES CONSIDERED}

1. Continue existing approach.

2. Use Total Quality and Value Engineering to improve process by el imination of unnecessary constraints.

\section{ARCHITECTURAL SYNTHESIS}

Considerable improvement in compliance cost is expected from elimination or modification or constraints which do not contribute to employee effectiveness, unnecessarily exceed industrial standards, or safety. 


\section{SYNTHESIS DEFINITION}

Use TQ and VE to enhance the existing process.

4.4.5.2 Develop Aqueous Waste Disposition Plan (4.5.2). Receives and determines the characteristics of the aqueous waste to be transferred, assesses the acceptability of the aqueous waste, and develops a plan for the disposition of the aqueous waste, identifies needs for improvements and additions. Scheduling of the waste transfer, treatment, and disposition is done later (in function 4.5.3). Information and intelligence function for managing aqueous waste. Input documentation will be associated with the waste which will provide compositions or a list of constituents of the waste being received, or appropriate waste codes.

\section{ALTERNATIVES CONSIDERED}

(To be considered in 1.0).

\section{ARCHITECTURAL SYNTHESIS}

( $T 0$ be considered in 1.0 ).

\section{SYNTHESIS DEFINITION}

(To be considered in 1.0 ).

4.4.5.3 Receive/Transport Aqueous Waste (4.5.3). Incoming aqueous waste is received, stored and/or transported to the aqueous waste treatment or disposal facilities including approval of the transfer request, scheduling and prioritization, transfer of the waste, and storage of the waste until it is treated. Associated with the waste will be all of the required documentation. Verification of the characteristics of the waste received, as well as monitoring the waste while in storage is also performed.

\section{ALTERNATIVES CONSIDERED}

1. Provide a combined facility collection system (TEDF--W-049H) for 200 Area effluents.

2. Provide a load-in station at the Effluent Treatment Facility (ETF) for the receipt of nonevaporator related aging waste (AW). Provide a transfer line for treated waste to the approved disposal site.

3. Provide a RCRA approved interim storage facility for 300 Area radioactive AW (W-302) destined for shipment to the 200 Area. Provide improved double wall rail cars for transfer.

4. Provide load-out stations at 100 Area fuel storage basins to allow AW truck/tanker shipments to the ETF. 
5. Provide an array of approved containers and vehicles to accommodate a variety of volumes and classifications of AW.

6. Receive and temporarily store 100 Area and 200 Area aqueous wastes (primarily 242-A Evaporator condensate) in LERF for subsequent treatment in the 200 Area ETF.

\section{ARCHITECTURAL SYNTHESIS}

Due to the lack of any DOT-approved conveyance for Type B liquid waste shipments, current practice relies upon control of site roads and railroad tracks, and SARP-derived approval. It is not feasible to build permanent bulk iqquid transfer systems between all waste generators and treatment facilities. Also, various lag storage facilities are needed to permit smooth operation of treatment facilities as well as bridging schedule disconnects.

\section{SYNTHESIS DEFINITION}

Provide a combined facility collection system for uncontaminated 200 Area aqueous wastes (200 Area TEDF). Receive and temporarily store 100 Area and 200 Area aqueous wastes contaminated with low levels of radioactive and hazardous materials in LERF. Identify other aqueous wastes needing treatment. Provide waste packaging, transport, load-in capability, and interim storage for aqueous wastes needing treatment. Retain flexibility to receive and treat aqueous wastes not currently identified as feeds to the 200 Area ETF, 200 Area TEDF, or 300 Area TEDF.

4.4.5.4 Treat Aqueous Waste (4.5.4). Treats the aqueous waste by whatever method has been developed in the Aqueous Waste Disposition Plan. During treatment, required stack, effluent, and process data are collected. The output streams from the treatment process may be stored, and during storage some waste verification may be performed, if necessary.

\section{ALTERNATIVES CONSIDERED}

1. Treat 300 Area aqueous wastes in the Treated Effluent Disposal Facility (TEDF) to meet river disposal requirements or otherwise as appropriate (e:g., ash sluice and filter backwash via L-059/V-791-b, 331, RLWS via $340 / 204-1 r$, etc.).

2. Treat 100 Area and 200 Area aqueous wastes which have low levels of radioactive and hazardous materials in the 200 Area ETF for eventual land disposal in the State Approved Land Disposal System (SALDS).

3. Provide some local treatment of 100 Area aqueous wastes.

4. Provide a single centrally-located effluent treatment facility to treat all aqueous wastes.

5. Develop applicable mobile treatment capability for use on small waste volumes or streams at remote locations. 
WHC-EP-0779

\section{ARCHITECTURAL SYNTHESIS}

Some aqueous waste from the 200 Area is contaminated by both radioactive and hazardous materials; other aqueous waste from the 200 Area has no such contamination. Aqueous waste from the 300 Area is about twice the volume and not radioactively-contaminated. The large volumes of waste and different treatment requirements preclude transporting the waste to a single treatment and disposal facility. The 300 Area sources are in close proximity to the Columbia River if disposal requirements are met. The SALDS is located in the 200 Area; its remote location affords time for decay of tritium before reaching the Columbia River. Other waste sources in the 100 Area and elsewhere on the Hanford Site are far removed from available treatment facilities.

\section{SYNTHESIS DEFINITION}

Treat 300 Area aqueous wastes in the 300 Area TEDF. Treat 100 Area and 200 Area aqueous wastes which have low levels of radioactive and hazardous materials in the 200 Area ETF. Provide some local treatment of 100 Area aqueous wastes. Investigate the need for and provide mobile treatment capability for small volume waste streams at remote locations.

\subsubsection{Disposition Aqueous Waste (4.5.5). Performs final disposition.} Waste may be disposed, reused, or released. Verification is performed to ensure that the waste meets a11 regulatory and permit requirements.

\section{ALTERNATIVES CONSIDERED}

1. Transfer treated nontritium containing aqueous wastes to municipal disposal

2. Contract treated nontritium containing wastes to commercial deposition.

3. Create treated effluent waste commercial capability on 200 Area plateau to meet mission requirements and provide disposal capability to privatization initiatives.

4. Dispose of 100 and 200 Areas treated aqueous wastes in existing permitted land disposal facilities.

5. Dispose of treated 300 Area aqueous wastes to the river.

\section{ARCHITECTURAL SYNTHESIS}

Ongoing operations require a continuation of existing disposal practices. Development of onsite commercial disposal has the potential attract new business to Hanford because of the generally restrictive atmosphere for aqueous waste disposal throughout the Nation. Commercial disposal of localized streams could provide a privatization resource beyond the site boundary. All streams which could be disposed by local municipalities should be transported offsite. 


\section{SYNTHESIS DEFINITION}

Use current practice of 1and/river disposal for near term. Develop local municipality disposal options. Develop onsite commercial disposal if trade studies show commercialization to be "mission" effective.

\subsubsection{Correct Unsafe Infrastructure Conditions (4.6)}

The CORRECT UNSAFE INFRASTRUCTURE CONDITIONS (4.6) function has a dual purpose, namely to correct all unsafe or noncompliant conditions as well as operation of all the services and facilities not identified with the programs or integrated cleanup activities. Infrastructure includes such items as roads, utilities, transportation, and office buildings.

\section{ALTERNATIVES CONSIDERED}

The alternatives for the infrastructure function set are documented in the Hanford Transition Initiative documentation (ref 7). These will be included in later versions of the alternatives document.

\section{ARCHITECTURAL SYNTHESIS}

$N / A$ 。

\section{SYNTHESIS DEFINITION}

N/A。

\subsubsection{Store, Treat, Disposition Special Nuclear Material/} Nuclear Material/Nuclear Fuel Materials (4.7)

The management of SNM, NM, and NF is the receiving, handling, processing, storing, and transfer for ultimate disposition of the materials in a safe and efficient way. SNM/NM/NF in this function includes plutonium as inventoried, uranium, thorium, retrieved special materials, irradiated fuel and other irradiated non waste materials, cesium and strontium capsules, and miscellaneous actinides such as neptunium and californium, and nuclear standards/sources.

\section{ALTERNATIVES CONSIDERED}

1. Store onsite until a National policy on disposition is available.

2. Designate SNM/NM/NF as waste and process for disposal within function 4.2 Remedy Tank waste.

3. Convert to a form suitable for beneficial use, and transfer ownership to new usage.

4. Transfer to offsite storage or disposition. 
WHC-EP-0779

\section{ARCHITECTURAL SYNTHESIS}

The definitions of some materials within this function continue to evolve. Most materials have not yet been designated as a waste, and are subject to National policy decisions remaining to be made. NEPA documentation is being developed for $\mathrm{Pu}$ bearing reactive materials and scrap and spent nuclear fuel. SNM/NM/NF should be stored onsite, and beneficial uses sought, until National policy and NEPA decisions have been determined.

As specified in the HDWEIS cesium and strontium these are scheduled for disposition as part of function 4.2 , However, the HDWEIS-ROD should be revisited to determine optimum disposition methods in the context of the overal1 cleanup system. SNM/NM/NF materials will be treated as required to ensure safe storage, SNM/NM/NF materials will be treated for disposition where reciever requirements are established.

\section{SYNTHESIS DEFINITION}

Store SNM/NF/NM until a national policy decision on their disposition is formulated. Reevaluate the ROD on cesium and strontium capsule disposition by vitrification in context of overall systems structure. Transfer to beneficial use wherever possible.

\subsubsection{Maintain Safety and Security Envelope (SNM/NM/NF) (4.7.1). Maintains the physical facility, qualified staff, safe and compliant equipment, documentation and provides assessment of safety and compliant states. Provides all necessary safety and security resources for compliance with all governing safety/security codes and regulations. Also included is the periodic verification of material inventory and sample analysis of the materials.}

\section{ALTERNATIVES CONSIDERED}

1. Continue existing safety and security approach at separate facilities, and consolidate materials when cost effective or the opportunity exists.

2. Employ a high tech security/storage/handling system to manage material security, safety and reliability.

3. Consolidate material storage/handling activities for comparable materials (similar chemical, security, etc.) utilizing existing facilities.

4. Consolidate material storage/handling activities for comparable materials (similar chemical, security, etc.) utilizing new or other compliant existing facilities.

5. Set security pesture to defend against highly organized and capable theft and terrorism.

6. Set security posture only to resist low capability (amateur) theft. 


\section{ARCHITECTURAL SYNTHESIS}

Existing Hanford storage facilities are aging, making interim upgrades or the construction of new facilities necessary to meet evolving needs and requirements. Security posture should be set by National policy for materials protection.

\section{SYNTHESIS DEFINITION}

Continue existing safety and security approach with necessary interim upgrades until a preferred longer term approach is selected. Continue to consolidate SNM/NM/NF where practical and cost effective.

4.4.7.2 Control SNM, NM, and NF Functions (4.7.2). Plans, coordinates, and schedules all the necessary operations within the 4.7 function. The function defines the treatment, storage, and transfer needs for the materials; establishes the acceptance criteria; and performs the acceptance or rejection of the material shipping documentation. The function does not include the physical work to perform the operations.

\section{ALTERNATIVES CONSIDERED}

1. Establish acceptance criteria and negotiate agreements to allow shipping or receiving of SNM/NM/NF .

2. Define and negotiate ultimate disposition to permit removal of SNM/NM/NF from storage.

3. Assess new requirements and negotiate waivers or modifications.

4. Establish storage and treatment criteria and negotiate alternatives (treatment and storage methodologies and design options).

5. Take proactive approach to SNM/NM/NF material management and forecast future receipts and dispositions to develop implementation plans.

6. Minimize management and $p l$ anning function and react to changes as they occur.

\section{ARCHITECTURAL SYNTHESIS}

The alternatives proposed here reflect handling, treatment, storage and disposition needs of SNM/NM/NF. Criteria should be defined and negotiated (and evaluated and updated as appropriate when criteria changes) for the receipt, storage, treatment and disposition of SNM/NM/NF based upon the unique requirements of different material types.

\section{SYNTHESIS DEFINITION}

Criteria for the receipt, storage, treatment and disposition of SNM/NM/NF will be defined and negotiated. 
4.4.7.3 Handle Incoming Materials (4.7.3). Physically handles the material shipping container and packaged material receipt. It is responsible for disposal of the wastes generated during the handling process.

\section{ALTERNATIVES CONSIDERED}

1. Return nonconforming packages to originator.

2. Accept nonconforming packages and upgrade as necessary.

3. Establish single mode criteria for receipt of materials.

4. Receive materials in any mode allowed by DOT.

5. Receive materials at a centralized location.

6. Receive materials into various satellite areas dependent upon the specific type of SNM/NM/NF material involved.

7. Receive, lag store, and recycle shipping containers.

8. Utilize certified packaging and containers for transport of SNM/NM/NF for onsite or offsite.

9. Obtain variances to utilize uncertified packaging and shipping containers for transport of SNM/NM/NF onsite or offsite.

\section{ARCHITECTURAL SYNTHESIS}

Incoming materials will be certified as required by function 4.7.2, however, non-conforming packages must be anticipated and dealt with. Return of non-conforming packages to the shipper is often impractical, therefore the capability for repackaging or decontamination must be available at the receiving site.

When non-conforming (i.e., non-certified) packaging is in the best interests of the complex, variances must be obtained. Incoming materials receipt location must be identical with subsequent treatment/storage architectures of function 4.7.4. Lag storage may be needed depending on the nature of the storage complex.

\section{SYNTHESIS DEFINITION}

Shipping containers and packaging of materials for shipping will be in certified packaging and containers. Materials receiving stations will have the capability to repackage or decontaminate non-conforming receivals.

4.4.7.4 Store Materials (4.7.4). Prepares and stabilizes the materials for storage and stores these materials until they are transferred to disposition. It is responsible for disposal of wastes generated during the material storage process. 


\section{ALTERNATIVES CONSIDERED}

1. Upgrade existing storage practice and facilities as needed to reduce storage risk until improved storage is available.

2. Create new facilities for long term storage, handling, and packaging of existing or new SNM/NM/NF.

3. Store SNM/NF/NM under conditions where the material containment package degradation is acceptable.

4. Continue to operate under jurisdiction of waivers until national policy decisions concerning SNM/NF/NM are in place.

5. Retrieve, package and store SNM/NF/NM to achieve high integrity storage in existing facilities.

6. Modify other existing facilities to provide handling, storage and packaging of existing or new SNM/NM/NF.

7. Store SNM/NM/NF in separate distinct storage facilities uniquely designed for the specific type of material or within existing facilities that are modified to store each specific type (or certain combinations) of material (i.e., Pu, U, Cs/Sr, SNF, unirradiated fuel, nuclear standards/sources, miscellaneous actinides, etc.).

8. Continue to store SNM/NM/NF in its present form and present locations.

9. Ascertain a best estimate of ultimate disposal condition, and treat materials to be compliant with this condition ASAP, preferable prior to storage.

\section{ARCHITECTURAL SYNTHESIS}

Continued use of aging facilities for storage will require significant upgrade costs and may not be consistent with ALARA best practices and long term cost effectiveness. New facilities are very expensive requiring long design and construction cycles and may have no better cost/risk benefit effectiveness. Studies are underway to determine the best alternatives for onsite storage.

Materials undergoing degradation in current storage conditions should be repackaged to provide the near term integrity needed to meet safety requirements and to prevent contamination spread.

Where treatment is necessary to provide safe storage, it will be performed. However, since the specific treatments and stabilization methodologies not only vary according to material type, but also may vary by the condition of specific packages within various material types, identification of specific treatment and stabilization options are not appropriate at this level. 
If options other than storage in existing locations are chosen, maintenance of current facilities until new facilities are ready for beneficial use, is required.

\section{SYNTHESIS DEFINITION}

The SNM/NM/NF will be stored in a safe storage mode, and treated where necessary to provide safe storage. Studies to determine the best alternatives for onsite material storage will continue.

4.4.7.5 Transfer Outgoing Materials for Disposition (4.7.5). Prepares, stabilizes, and transfers materials for disposition. The disposition of materials is one of two processes: the transfer of useable material or the transfer of materials for disposal. It arranges for disposal of incidental wastes generated during the disposition process.

\section{ALTERNATIVES CONSIDERED}

1. Construct temporary facility(s) to perform packaging and shipping preparation on an as-needed basis.

2. Include packaging/shipping facility in new interim storage complex.

3. Modify and/or maintain existing facilities to perform SNM/NM/NF packaging and shipping.

4. Instal1 general purpose treatment facilities in new or modified existing facilities for treatment prior to disposition.

5. Anticipate that the storage and treatment facility capabilities required for safe storage will be appropriate for disposition treatment.

6. Provide facility space for disposition treatment equipment but hold disposition treatment design activity until receiver acceptance criteria is established.

\section{ARCHITECTURAL SYNTHESIS}

Packaging/shipping facilities for final disposition should be included in either a new storage facility or in a modified existing facility. Treatment for disposition is yet to be defined. Specification of disposition treatment methods is inappropriate until receiver acceptance criteria is firm.

\section{SYNTHESIS DEFINITION}

Packaging/shipping facilities should be included in either a new storage facility or modified existing facility. 


\subsection{TRANSITION RESOURCES FOR BENEFICIAL USE}

The TRANSITION RESOURCES FOR BENEFICIAL USE function provides for the disposal of excess land, materials and personnel; recycling of material, facilities, equipment and personnel to uses within the mission; and smooth economic transition to a viable local economy as the cleanup mission winds down.

\section{ALTERNATIVES CONSIDERED}

1. Approach to determination of new uses - Highly active involving notices in $\mathrm{CBD}$, customer tours, product fairs, Cooperative Research and Development Agreements, or more passive methods relying on new user initiatives to identify transfer opportunities.

2. Centralized or dispersed activity - Development of individual transfer activities within each major program or establishment of a separate organization specifically directed to maximize transfer actions.

3. Develop in-house resource upgrade capability or private offsite resources.

\section{ARCHITECTURAL SYNTHESIS}

Effective transfer of Mission resources is similar to a commercial "sales" operation. To be effective the sales methods used in commercial marketing will be needed. If the effort is buried within other architectures, the transfer work will be de-emphasized with respect to the primary product line. Using privatized upgrade capability will assist local business development.

\section{SYNTHESIS DEFINITION}

The resource transfer approach consists of a centralized organization which aggressively pursues transfer of wastes, excess equipment, infrastructure, and personnel to new applications inside and outside the mission.

\subsubsection{Determine Beneficial Uses of Resources (5.1)}

The DETERMINE BENEFICIAL USES OF RESOURCES (5.1) function determines which resources are candidates for use outside the mission, seeks "customers" to receive the resources, and establishes agreements to actually transfer specific items, as well as personnel.

\section{ALTERNATIVES CONSIDERED}

1. Conduct resource identification activities using a private entity.

2. Conduct resource identification using DOE prime contractors and their subcontractors. 
3. Reserve materials with a high future use probability without identification of a verifiable customer.

4. Consider all mission materials as "waste" or surplus until a customer is identified.

\section{ARCHITECTURAL SYNTHESIS}

No clear advantage for either the private entity and DOE contractor approach is evident. For the purposes of further defining the system the Contractor approach is assumed. Preservation of resources or waste materials without a confirmed future use must be avoided if the mission is to succeed.

\section{SYNTHESIS DEFINITION}

Transferable resources will be identified as those which have an identified and confirmed future use. This identification will be conducted by an assigned DOE contractor. 
This page intentionally left blank. 


\subsection{REFERENCES}

1) J.J. Holmes, "Systems Engineering Functions and Requirements For the Hanford Cleanup Mission: First Issue", WHC-EP-0722, (January 1994)

2) MIL-STD, 1993, Systems Engineering, Draft Military Standard, MIL-STD-499B, (September 7, 1993)

3) Systems Engineering Management Counci1, Defense Systems Management College, Fort Belvoir, VA

4) 89-10 Rev. 3, Hanford Federal Facility Agreement and Consent Order, Fourth Amendment, (January 1994)

5) WHC-EP-0549, Hanford Strategic Analys is Study, Draft C, (November 1993)

6) DOE/RL-93-102, 1995 Hanford Mission Plan, Volume 1, Site Guidance, (March 1994)

7) "Infrastructure Transition Initiative", Draft, Volume I Report by the ITI Core Team

8) DOE/RL-92-60, "Tank Waste Remediation System Functions and Requirements", Draft, (March 1993) DOE-RL, 1993, Tank Waste Remediation System Functions and Requirements, DOE/RL-92-60, Draft, U.S. Department of Energy, Richland Operations Office, Richland, Washington. 
WHC-EP-0779

DRAFT

This page intentionally left blank. 


\section{DISTRIBUTION}

Number of copies

ONSITE

W. T. Alumkal

S7-85

K. B. Bailey

LO-14

M. S. Bensky

LO-06

R. J.Bliss

R3-50

R. R. Borisch

R3-56

M. K. Britton

B4-54

J. L. Collings

LO- 14

G.

B5-32

D. E. Deichman

J. C. Fulton

H4- 19

M. L. Grygiel

R3-85

R. M. Hadley

B1 -58

K. L. Hladek

G1-56

J. J. Holmes (10)

H5-33

J. 0 . Honeyman

LO-14

G. W. Jackson

S7-81

C. N. Krohn

H6-21

B. S. Kuntz

L0-06

D. P. Lund

B3-25

H. E. McGuire

R3-56

D. E. McKenney

B3-63

S. K. Murdock

N3-10

D. H. Nyman

F.J. Orsag

B3-35

G6-06

S. M. O'Toole

B1-58

D. T. Romine

H5-38

J. D. Schaffer

H6-27

S. E. Seeman

N1-71

P. K. Shen

LO-06

J. M. Steffen

V. R. Weil

G. W. White

HO-39

$\mathrm{N} 1-47$

J. D. Williams

G3-10

B3-35

J. C. Womack

T. W. Woods

H6-28

R3-85

JJH File/LB

H6-2I

Correspondence Control

LO- 14

Central Files

A3-01

Information Release

L8-04

Administration (3)

L8-07 


\section{DISTRIBUTION (Continued)}

Number of copies

ONSITE

7

U. S. Department of Energy,

Richland Operations Office

R. 0. Puthoff (w/o attach.)

A5- 10

J. D. Kautzky

A5-04

W. A. Rutherford (5)

A5-04

6

Pacific Northwest Laboratory

W. A. Hesser

J. A. Mahaffey

K8-10

M. J. Simpson

M. B. Triplett

P7 -82

K7 -97

Public Reading Room

K7 -90

Technical Files

Al-65

$\mathrm{K} 1-11$

1

ICF Kaiser Hanford

R. H. Beers

B4-52

1

BCS Richland. Inc.

T. 0. Elsethagen

A2-50

1

Hanford Environmental

Health Foundation

R. H. Ronish

HI-75

1

MAC Technical Services Company

W. M. Ritter

A4-35 